\title{
A systematic review of resting state functional MRI connectivity changes and cognitive impairment in multiple sclerosis
}

Danka Jandric ${ }^{1^{*}}$, Anisha Doshi ${ }^{2 *}$, Richelle Scott $^{1}$, David Paling ${ }^{3}$, David Rog ${ }^{4}$, Jeremy Chataway ${ }^{2}$, Menno Schoonheim ${ }^{5}$, Geoff Parker ${ }^{1,6}$, Nils Muhlert ${ }^{1 \dagger}$

*Joint first authors

${ }^{\dagger}$ Corresponding author

${ }^{1}$ Division of Neuroscience \& Experimental Psychology, School of Biological Sciences, Faculty of Biology, Medicine and Health, University of Manchester, Manchester Academic Health

Science Centre, Manchester, UK

${ }^{2}$ Queen Square Multiple Sclerosis Centre, Department of Neuroinflammation, UCL Institute of Neurology, Faculty of Brain Sciences, University College London, UK

${ }^{3}$ Royal Hallamshire Hospital, Sheffield Teaching Hospitals, NHS UK

${ }^{4}$ Salford Royal Hospital, Salford Royal NHS Foundation Trust, NHS UK

${ }^{5}$ Department of Anatomy and Neurosciences, MS Center Amsterdam, Amsterdam Neuroscience, Amsterdam UMC, Vrije Universiteit Amsterdam, Amsterdam,

The Netherlands.

${ }^{6}$ Centre for Medical Image Computing, Department of Computer Science and Department of Neuroinflammation, Queen Square Institute of Neurology, University College London, London, UK 


\begin{abstract}
Cognitive impairment is common in multiple sclerosis (MS) and resting state functional MRI (rsfMRI) functional connectivity (FC) is increasingly used to study its pathophysiology. However, results remain difficult to interpret, showing both high and low FC associated with cognitive impairment. We conducted a systematic review of rs-fMRI studies in MS to understand whether the direction of FC change relates to cognitive dysfunction, and how this may be influenced by the choice of methodology. Embase, Medline and PsycINFO were searched for studies assessing cognitive function and rs-fMRI FC in adults with MS. Fifty-seven studies were included in a narrative synthesis. Of these, 50 found an association between cognitive impairment and FC abnormalities. Worse cognition was linked to high FC in 18 studies, and to low FC in 17 studies. Nine studies found patterns of both high and low FC related to poor cognitive performance, in different regions or for different MR metrics. There was no clear link to increased FC during early stages of MS and reduced FC in later stages, as predicted by common models of MS pathology. Throughout, we found substantial heterogeneity in study methodology, and carefully consider how this may impact on the observed findings. These results indicate an urgent need for greater standardisation in the field - in the choice of MRI analysis and the definition of cognitive impairment. Through this we will be closer to using rs-fMRI FC as a biomarker in clinical studies, and as a tool to understand mechanisms underpinning cognitive symptoms in MS.
\end{abstract}




\section{Key points}

- Cognitive impairment in multiple sclerosis (MS) is increasingly being researched with advanced magnetic resonance imaging (MRI) measures, including resting state functional MRI (rs-fMRI)

- The rs-fMRI functional connectivity (FC) metric is associated with cognitive impairment, and has the potential to be a biomarker of cognitive decline.

- A main challenge to developing a FC biomarker is the lack of consistency in the direction of FC changes associated with cognitive impairment, with cognitive deficits associated with both lower and higher FC.

- FC changes don't appear to be linked to clinical and methodological factors such as disease phenotype, disease duration and brain region or network studied.

- Overall, there is substantial heterogeneity in study methodology, suggesting an acute need to standardise the study of cognitive impairment in MS and its investigation by rsfMRI methods. 


\section{Abbreviations}

BICAMS - Brief International Cognitive Assessment for Multiple Sclerosis

BMS - Benign Multiple Sclerosis

BOLD - Blood-Oxygenation-Level-Dependent

CI - Cognitively Impaired

CIS - Clinically Isolated Syndrome

$\mathrm{CP}-$ Cognitively Preserved

DMN - Default Mode Network

EDSS - Expanded Disability Status Scale

FC - Functional Connectivity

ICA - Independent Component Analysis

MACFIMS - Minimal Assessment of Cognitive Function in Multiple Sclerosis

MRI - Magnetic Resonance Imaging

MS - Multiple Sclerosis

PASAT - Paced Auditory Serial Addition Test

PPMS - Primary Progressive Multiple Sclerosis

PRISMA - Preferred Reporting Items for Systematic Reviews and Meta-Analysis

PROSPERO - International Prospective Register of Systematic Reviews

ROI - Region Of Interest

RRMS - Relapsing-Remitting Multiple Sclerosis

Rs-fMRI Resting State Functional MRI 
medRxiv preprint doi: https://doi.org/10.1101/2021.03.18.21253878; this version posted March 20, 2021. The copyright holder for this preprint (which was not certified by peer review) is the author/funder, who has granted medRxiv a license to display the preprint in perpetuity.

All rights reserved. No reuse allowed without permission.

RSN - Resting State Network

SCA - Seed Based Connectivity Analysis

SDMT - Symbol Digit Modalities Test

SPMS - Secondary Progressive Multiple Sclerosis 


\section{1}

2

3

4

Multiple sclerosis (MS) is a chronic immune mediated disorder of the central nervous system that predominantly affects young adults (1-3). Inflammatory demyelination is pathognomonic with neurodegeneration insidiously dominating over time (4).

Cognitive impairment is common in all MS phenotypes (5-7) with an estimated prevalence of $43-70 \%$ dependent on factors including phenotype and the cognitive diagnostic criteria used $(8,9)$. Cognitive impairment is associated with several adverse outcomes including a higher risk of depression, unemployment and reduced quality of life (9-11). A more progressive MS phenotype and longer disease duration have been shown to be associated with greater cognitive impairment (12-16). There are currently no licensed treatments for cognitive symptoms in MS, however exercise (17) and behavioural therapy show promise (18). Disease modifying therapies show positive outcomes on cognitive dysfunction in MS, despite no routine evaluation in phase 3 clinical trials currently. However, effects are small and at present understudied, and there are to date no approved pharmaceutical treatments for cognitive symptoms $(7,19)$.

Gaining an understanding of the underlying pathophysiology of cognitive dysfunction is essential for diagnosing, monitoring and developing treatments for this debilitating aspect of MS. The 'clinico-radiological' paradox highlights the mismatch of MS cognitive symptoms and conventional Magnetic Resonance Imaging (MRI) measures, such as lesion volumes (20). It is widely accepted that cognitive function is supported by a complex network of structurally interconnected brain regions supporting a highly dynamic functional network, which is researched with advanced MRI tools such as resting state functional MRI (rs-fMRI), in MS and other neurodegenerative diseases (20-24).

The main measure derived from rs-fMRI is the functional connectivity (FC) metric. It is a measure of the statistical correlation of blood-oxygenation-level-dependent (BOLD) signal time 
course between any selection of voxels. The underlying assumption is that voxels with similar BOLD time courses are connected in the performance of a function (25), see Figure 1. FC has the potential to be an imaging biomarker of cognitive performance in neurodegenerative disease (26) and is the subject of a growing research field in MS (7). Such a marker could offer a fast, non-invasive way to detect imminent cognitive decline, which is often underdiagnosed on routine neurological examinations (27). For a measure to be suitable as a clinical biomarker, it needs to be able to identify those with cognitive dysfunction from those without it, and to show acceptable repeatability and reproducibility across studies. In some diseases, like Alzheimer's disease, the rs-fMRI literature shows consistently low FC in the default mode network (DMN) (28), yet a recent review of rs-fMRI studies in several neurodegenerative diseases, including Alzheimer's, argued that the evidence is not yet strong enough for rs-fMRI FC measures to be suitable biomarkers (26). This review cited a lack of standardised protocols as a challenge in the field.

The rs-fMRI FC literature on cognition in MS has not yet been subject to systematic review, and so the specificity and reliability of $\mathrm{FC}$ as a marker of cognitive dysfunction has not been established. Correlations between FC metrics and cognition have been frequently reported (2932), but in studies comparing FC between cognitively impaired (CI) and cognitively preserved (CP) patients, results have shown both high and low FC linked with worse cognitive function (33-37). A common interpretation of increases in any type of brain function is that of functional "reorganisation": a compensatory mechanism that enables the functioning of networks in the presence of structural damage, hence delaying clinical progression. This compensatory mechanism is thought to be sustainable only up to a critical point, at which the structural damage becomes too great to compensate for, leading to the hypothesized "network collapse", manifested as decreases in FC and clinical progression $(38,39)$. In support of this, several studies indicate different patterns of FC changes at different disease stages, such as high FC in clinically isolated syndrome (CIS), the earliest stage of MS, and low FC in progressive MS (35,40-43). However, high FC has also been related to the severity of impairment (29), casting doubt on the beneficial nature of these changes. As such, it is not yet clear whether the pattern of results from rs-fMRI studies consistently fits the predictions of this model. This may be complicated by the 
medRxiv preprint doi: https://doi.org/10.1101/2021.03.18.21253878; this version posted March 20, 2021. The copyright holder for this preprint (which was not certified by peer review) is the author/funder, who has granted medRxiv a license to display the preprint in perpetuity.

All rights reserved. No reuse allowed without permission.

59 heterogeneity in methodological aspects of studies which could influence the direction of

60 findings (44).

61 In this study we carry out a systematic review of rs-fMRI FC studies of cognitive dysfunction in

62 MS to outline the state of the field and provide a critical analysis of findings to date. We

63 considered directionality of results and the influence of methodological aspects on findings of

64 FC alterations. Through doing so we offer key points that need to be addressed in order to 65 develop a parsimonious account of why FC may change in MS and what it may mean for clinical 66 practice.

67

68

Method

Protocol and Registration

70 The design of the systematic review and manuscript preparation were based on the Preferred

71 Reporting Items for Systematic Reviews and Meta-Analysis (PRISMA) guidelines (45). The

72 systematic review protocol was developed in advance and, in accordance with PRISMA

73 guidelines, registered with the International Prospective Register of Systematic Reviews

74 (PROSPERO) on 18 May 2020, and last updated on 31/8/2020 (registration number

75 CRD42020154415).

76

77 Information sources and search strategy

78 Literature searches were conducted in Embase (accessed through the Ovid interface, 1974

79 onwards), Medline (accessed through Ovid, 1946 onwards), and PsycINFO (accessed through

80 Ovid, 1806 onwards) on $31^{\text {st }}$ October 2019, with no limits imposed on the searches. The search

81 strategy used terms for 'multiple sclerosis' 'functional connectivity' and 'cognition' and was

82 tailored for each database to use both controlled terms where available and uncontrolled

83 keywords in order to capture any synonym, abbreviation and related term of the keywords of

84 interest. The searches were repeated on $22^{\text {nd }}$ October 2020 to capture any studies published since

85 the original searches. The same search strategy was used, but limits were added to capture only 
results which had been added or updated in the period $1^{\text {st }}$ November $2019-22^{\text {nd }}$ October 2020. The full search strategy used in each database is available in Supplementary Table 1.

\section{Study eligibility and selection}

91 Records returned by each search were imported into the Mendeley reference management

92 software v 1.19.4, and duplicates were removed using the tool's de-duplication function. Titles

93 and abstracts were then manually screened by two independent reviewers (DJ and RS). Full text

94 publications were obtained for all papers chosen for full text review by one or both reviewers and

95 assessed for inclusion in the review against pre-defined eligibility criteria. Any disagreements

96 about study inclusion were resolved through discussion and reasons for study exclusion were

97 recorded. This process was then repeated for the search conducted on $22^{\text {nd }}$ October 2020. The

98 results at each stage, for the combined two searches, are presented in Figure 2.

Eligibility criteria were: original peer-reviewed research studies reporting on cognitive function

101 and FC metrics derived from rs-fMRI in adult MS patients. Review articles, book chapters and conference abstracts were excluded, as were any original research studies in a paediatric population, on diseases other than MS, studies which had not measured cognitive function and/or functional connectivity, studies focusing on cognitive rehabilitation, studies which had assessed social cognition only, and any articles which were not available in English.

\section{Data collection and synthesis}

Data extraction was performed by DJ and RS and the following data items were recorded: 1) study characteristics (authors, year of publication, journal); 2) aims of the study; 3) Participant details (MS subtype, control group, sample size, disease duration of MS sample, Expanded Disability Status Scale (EDSS) score of MS sample); 4) MR methodology (scanner field

112 strength, MR metrics); 5) FC analysis (data pre-processing, method for analysis, whether analysis was global or regional [and if so, which regions], use of covariates); 6) cognitive testing 
medRxiv preprint doi: https://doi.org/10.1101/2021.03.18.21253878; this version posted March 20, 2021. The copyright holder for this preprint (which was not certified by peer review) is the author/funder, who has granted medRxiv a license to display the preprint in perpetuity.

All rights reserved. No reuse allowed without permission.

114 (cognitive test(s) used, definition of cognitive impairment, number of cognitively 115 impaired/preserved patients if applicable); 7) results from FC analysis and from other MR 116 metrics).

To understand whether there might be a link between methodological aspects and FC results, we examined whether a particular feature was commonly present in studies that report links between worse cognition and either high or low FC. The features we examined were the MS subgroup studied, the average disease duration of patient samples, the rs-fMRI analysis method and the

122 brain region or resting state network (RSN) investigated. Because the studies included were too 123 heterogeneous for a meta-analysis, data synthesis was done by tallying the number of studies 124 sharing a specific methodological feature or FC result.

\section{Assessment of study quality}

127 A quality assessment approach was chosen over a risk of bias tool because most articles for 128 inclusion in this review were expected to be cross-sectional. The AXIS tool was designed for cross-sectional studies across a range of scientific disciplines (46) and was therefore selected to 130 judge the quality of the evidence included in the review. The AXIS tool is a 20 item checklist 131 which asks 'yes/no' questions about important elements of a study. Three of the 20 items in the tool were not relevant for the studies selected for this review, as they refer to responding to an intervention, so quality assessment was based on the remaining 17 items. The items of the AXIS

134 tool are not scored, but instead recorded in a similar way to the Cochrane risk of bias tool (47), 135 allowing review authors to make an overall assessment of the quality of the study based on the 136 presence or absence of reporting of the items covered by the tool.

Results 
The systematic review process is outlined in Figure 2. The database searches yielded 2061 results, and in addition 6 were identified from other sources. After removal of duplicates 1697 remained, which were screened for eligibility until 177 remained for full-text assessment. At this point 120 records were excluded, most of which were conference abstracts (see Figure 1 for reasons for exclusion). Fifty-seven studies met eligibility criteria and were included in the review. These studies are summarised in Table 1. All studies were of high quality, as measured by the AXIS tool (46). Eighteen studies did not include clear details of where participants were recruited from for the study, and very few studies $(5 / 57)$ had a justification for the sample size used.

\section{Participant characteristics}

The studies that were included differed in the clinical and demographic details of the MS samples used. The majority of studies used a mixed sample of different MS phenotypes (29/57 studies), and slightly over a third used a sample of relapsing-remitting MS (RRMS) patients only (22/57 studies). The remaining six studies used either a primary progressive MS (PPMS) sample (1/57), CIS sample (2/57), a benign MS (BMS) sample (1/57) or did not specify the MS subtype (2/57). See Table 1 for details on the cohort of each study.

The average disease duration ranged from as little as 4.2 months (48) to 21.9 years (49) from either time from first symptom or from diagnosis, and median EDSS ranging from $1(34,48)$ to $6.5(50)$.

Most studies (54/57) used healthy volunteers as a control group. In one study normative data from age-matched healthy controls was used for neuropsychological assessments, but no control group was used for comparisons of MRI metrics (50). In one study no control group was specified (51), and in one longitudinal study no control group was used (52). Out of the studies using healthy controls, many did not report matching groups on any demographic variables $(18 / 54)$ while some reported matching groups but not on which variables (3/54) and one reported not matching the groups. Of the studies reporting the variables groups were matched on, most 
169

170

171

172

173

174

175

176

177

178

179

180

181

182

183

184

185

186

187

188

189

190

191

192

193

194

were on age and sex (15/54), followed by age, sex and education (10/54), age only (2/54), sex only $(2 / 54)$ or age, sex, education and premorbid IQ (1/54). In this review we have interpreted the words 'sex' and 'gender' to both refer to sex, given that MS is a disease characterised by sex differences in prevalence $(2,53)$.

\section{Neuropsychological assessment}

Most studies (34/57) looked at relationships between cognitive test performance and MR metrics through correlations or regressions, and 19 studies examined group differences in MR metrics between patients who met criteria for cognitive impairment and those who did not. Of the remaining four studies, one looked at FC only in MS patients with intact spatial memory (41), and three did not directly assess the relationship between cognition and FC. Despite this, they were included in the review for the following reasons: the authors of one study expressed intentions to correlate FC measures with clinical measures, but did not because the FC measure did not show any abnormalities in MS patients (54); two studies indirectly explored the relationship between FC and cognition and did not meet any exclusion criteria $(55,56)$.

To assess cognitive function most studies used either the Brief Repeatable Battery of Neuropsychological tests (BRB-N), which has been validated for use in MS (57), alone or in combination with other tests (20/57), or a collection of individual tests (14/57). The remaining studies used either another cognitive battery; Brief International Cognitive Assessment for MS (BICAMS) n=2 (58), Minimal Assessment of Cognitive Function in MS (MACFIMS) n=2 (59), Mini Mental State examination $\mathrm{n}=1$ ), or a single test; Paced Auditory Serial Addition Test (PASAT) n=6, Symbol Digit Modalities Test (SDMT) n=1, Location Learning Test $n=1$, Short test of mental status $n=1$, the computerised test of information processing $n=1$ ) or a cognitive reserve index $(n=1)$. The specific battery or tests used by each study are summarised in Table 1 . 
205

206

207

208

209

210

211

212

213

Within the 19 studies that split the MS sample into cognitively impaired and cognitively preserved sub-samples, there were 12 different definitions of cognitive impairment. Some definitions are likely guided by the test(s) used to assess cognition, but even amongst studies using the BRB-N, there were five different definitions of cognitive impairment. These include: $\geq 1.5$ SD below normative values on $\geq 1$ test $(n=1) ; \geq 1.5$ SD below controls scores on $\geq 2$ tests ( $n=5$, but note that four used this definition of a mildly cognitively impaired group), $\geq 2$ SD below normative values on $\geq 1$ test $(n=1)$; $\geq 2$ SD below normative values on $\geq 2$ tests $(n=9)$; performance in the $5^{\text {th }}$ percentile of scores on either the Selective Reminding Test or Spatial Recall Test compared to normative data $(n=1)$.

\section{Functional connectivity analysis}

Half of all studies (28/57) used a seed-based connectivity analysis (SCA) method for assessing FC. In this category we have included studies which used one or a few specific regions of interests (ROIs; regional SCA) or divided the whole brain into ROIs and created a connectivity matrix (global SCA). The second most common method was independent component analysis (ICA) (14/57), and the remaining studies either calculated graph theory metrics (7/45), used a principal component analysis (1/45) or used a combination of SCA and graph theory (1/45) or ICA and graph theory (1/45). See Table 1 for the design and rs-fMRI analysis method of each study.

A wide range of regions and RSNs were investigated, either as a priori defined areas of interest, or as patterns emerging from a data-driven analysis, of which the most common were the DMN (21/57), thalamus and thalamic networks (9/57), the fronto-parietal network (FPN), including the right, left, dorsal and ventral FPNs (7/57). Other RSNs and regions investigated include the attentional network including left, right, dorsal, ventral variants, the salience network, the executive network, the working memory network, the motor network, the sensorimotor network, the visual processing network, the auditory network, the auditory and language processing network, visual processing networks, including medial and lateral variants, the cerebellar network, the medial prefrontal cortex, anterior cingulate cortex, posterior cingulate cortex, 
medRxiv preprint doi: https://doi.org/10.1101/2021.03.18.21253878; this version posted March 20, 2021. The copyright holder for this preprint (which was not certified by peer review) is the author/funder, who has granted medRxiv a license to display the preprint in perpetuity.

All rights reserved. No reuse allowed without permission.

225 precuneus, basal ganglia, hippocampus and cerebellum. Ten studies conducted a whole-brain

226 analysis and did not report regional FC changes. See Supplementary Table 2 for an overview of

227 study results by regions investigated.

\section{Functional connectivity results}

232 The main result of the relationship between FC and cognition of each study is summarised in

233 Table 1 and Figure 3. Overall, 18 studies found worse cognition to be linked with high FC and

23417 found it to be associated with low FC. Nine studies found patterns of both high and low FC to

235 be associated with cognitive impairment, in different regions or for different MR metrics, and

236 seven studies found no significant relationship between cognitive and FC measures. Six studies

237 had a methodology which didn't measure the direction of FC change in relation to cognitive

238 impairment.

240 When grouping studies based on methodological and clinical features to assess whether one

241 direction of FC change associated with worse cognition is more commonly seen in studies with

242 that feature, we found no trend to suggest that one FC direction change associated with worse

243 cognition is more commonly seen in studies using a specific method or studying a specific type

244 of sample. This includes grouping studies based on the RSN or network assessed. Of the 21

245 studies measuring FC in the DMN, 10 found worse cognition to be associated with low FC, 6

246 with high FC, 1 with both high and low FC, 3 obtained a negative result, and one study did not

247 test the relationship directly, see Supplementary Table 2.

249 We ordered studies by the average reported disease duration of the sample used, to see if patterns

250 of FC changes differ from early to late in the disease and found no such trend, see Figure 4 and

251 Supplementary Table 3. 
253 We also considered the role of phenotype, however, most studies used either a mixed sample 254 consisting of several phenotypes or a sample of RRMS patients only. Of the 22 studies which

255 used a RRMS sample, eleven reported worse cognition to be associated with high FC and ten 256 with low FC. Three studies reported a negative result and one had a study method which does not 257 inform about the direction of FC changes. Similarly, within the mixed sample studies almost half 258 of studies reported worse cognition to be associated with high FC (13/29) and more than half 259 with low FC (16/29). Some studies reported both high and low FC to be associated with worse cognitive function and have therefore been counted twice. See Supplementary Figure 1 for an overview. In seven of the studies with mixed phenotype samples subgroup analyses were conducted to compare FC changes between different MS phenotypes in the sample, but only two included cognition in these analyses. One found a stronger positive correlation between FC in the DMN and errors on the PASAT in secondary progressive MS (SPMS) compared to RRMS, while another found differences between RRMS and SPMS in the spatial location of FC abnormalities that corelated with cognitive test performance.

\section{Discussion}

In this systematic review we examined the consistency and direction of findings of studies investigating associations between rs-fMRI FC measures and cognition in MS. Overall, the

271 studies reviewed support the notion of FC alterations associated with cognitive dysfunction in

272 MS (Filippi and Rocca, 2013). Although most changes were related to cognitive dysfunction, the 273 direction of FC changes varied considerably between studies and was not clearly linked to any 274 methodological factors. There was substantial heterogeneity in clinical and rs-fMRI 275 methodology, as has previously been noted in non-imaging cognition studies in MS (7,9). We 276 therefore consider ways in which the field can reflect on what has been learned to date and 277 improve future study designs to more clearly understand the mechanisms and consequences of changes in rs-fMRI FC. 
The most commonly used model for understanding FC changes in MS is the 'network collapse' model, which postulates three main stages (38). In the first, early stage network efficiency remains normal, at this point structural damage can be compensated by increases in local activation. This predicts early increases in FC, reflecting these compensatory processes. The second stage is where structural damage accrues to a critical point, at which compensatory processes become less effective. Finally, in the third stage structural damage exceeds the critical point with associated 'network collapse', and concomitant decreases in FC. Computational modelling of empirical data on FC in MS supports this model (44). Similarly, longitudinal studies demonstrate a reorganisation of structural and functional networks in early stages of MS (i.e. CIS) despite intact cognitive performance, suggesting compensatory processes are at work (48). Cross-sectional task-related fMRI studies also indicate increasing deviation from healthy control patterns of brain activation during cognitive tasks, consistent with functional reorganization, as patients progress from CIS to RRMS to secondary progressive MS (62). Together, these theories predict early adaptive reorganization of functional networks, followed by a failure of effective network organization in MS over time (see also Chard et al., 2021).

In our review, when ordering studies by the average disease duration of the sample, we did not observe a trend in the direction of FC findings from early to advanced MS, as predicted by the network collapse model. We therefore consider whether the lack of fit to the model relates to the particular samples or methods of analysis employed. Many of the studies included in this review used samples of mixed phenotypes. MS phenotype has previously been reported to influence resting network FC alterations, so the inclusion of mixed MS samples could contribute to the lack of consistency in findings. However, in our review only two studies assessed the relationship between FC, phenotype and cognition, and these found both abnormally increased (64) and abnormally decreased (36) FC in patients with progressive MS. This suggests that even in specific MS subgroups, there remains considerable variability in the direction of findings. More evidence is needed in order to determine whether FC changes vary between phenotypes, and whether any model of network changes has different explanatory power for the different phenotypes. A further important consideration is the effect of disease duration and how it may mediate the relationship between FC, phenotype and cognition. Longer disease duration in 
RRMS is associated with FC changes in attentional, executive, and default mode networks (65). This suggests that disease duration may have an important influence on FC changes associated with cognitive impairment, possibly due to increased structural damage with longer disease duration. Those studying patients with longer disease duration (such as those with SPMS) will also have to account for age-related atrophy in these samples (66), which will be exacerbated when studying those patients with relapsing as well as progressive subtypes of MS.

We also considered whether the direction of FC change relates to definitions of cognitive impairment and choice of FC analysis. Studies of cognition in MS use a vast array of definitions of cognitive impairment (7-9), as reflected in this review. For example, of the studies using the BRB-N to assess cognitive function, most use a more conservative definition of cognitive impairment of at least 2 SDs below controls on 2 or more tests $(23,36,67-73)$, but other, less conservative definitions are used too $(37,74,75)$. The definition of cognitive impairment has been shown to have effects on underlying FC alterations of MS CI by the classification used (76). A few studies have compared different thresholds of cognitive impairment and found the greatest FC abnormalities in those participants meeting the more conservative thresholds (i.e. more than 2 standard deviations from controls on 2 or more tests). In contrast, less clear FC abnormalities were observed in samples performing between 1.5 and 2 SDs below controls on 2 tests ("mild cognitive impairment") $(23,70,76,77)$. This demonstrates the possible effect of the definition of cognitive impairment on FC findings and the arbitrary nature of these thresholds. Such findings highlight the importance of using a consistent measure of cognitive dysfunction and definition of impairment across studies. As a further challenge there is no established specific cognitive test or battery for defining cognitive dysfunction in MS despite documented phenotypic differences in impairments by test and domain $(13,14,78,79)$. Separately, we found scant evidence to support a consistent direction of FC change in cognitively impaired patients when using model-based (e.g. seed) or data driven (e.g. ICA) approaches, or when considering specific resting state networks. Indeed the default mode network, the most commonly studied RSN across the literature, showed both increases and decreases in cognitively impaired MS patients (see supplementary Table 2). 
There also needs to be a greater understanding of the mechanisms through which FC changes in MS. The 'network collapse' model suggests that network efficiency reduction is a function of accumulation of structural damage. In support of this, work focusing on structural connectivity in MS has found consistent evidence for structural network alterations associated with cognitive dysfunction (80-82). However, these studies have considered white matter in isolation, so conclusions about the effect of anatomical network changes including grey matter on functional connectivity cannot be drawn. In contrast, multimodal MRI studies of diffusion-weighted MRI (DWI) and rs-fMRI can assess the relationship between changes in structural and functional connectivity. Those that have been conducted support the influence of alterations in white matter linked to FC abnormalities in MS, and fit the predictions of the 'network collapse' model (44,83-85). Future multimodal studies using DWI and rs-fMRI can test the predictions of the 'network collapse' model further and to develop this or new models as needed to better characterise progression and the influence of pathology in MS brains, in order to develop clinically useful disease markers. In addition, there is evidence of physiological abnormalities in MS that are associated with cognitive dysfunction, such as cerebral hypoperfusion and sodium accumulation in the grey and white matter (86-88), and additional proton spectroscopic changes (89). Considering how these are related to network changes can help us understand the mechanisms of network abnormalities and aid in the search for a biomarker of cognitive impairment.

This systematic review provides a call to arms for the need to standardize the study of cognitive impairment in MS, but also the use of specific rs-fMRI methodology and interpretations of results. Ten years ago Fox and Greicius (2010) identified inconsistent results of FC changes across rs-fMRI studies as a barrier to the clinical applicability of this modality, and suggested a set of guidelines for rs-fMRI studies of clinical populations (90). Despite this, heterogeneity in study methodology seems to be a challenge across neurodegenerative diseases investigated by rsfMRI, and the rs-fMRI derived FC measure is not yet suitable as a biomarker of disease (reviewed by Hohenfeld et al., 2018). In this review we have shown that MS is no exception; there is considerable variability in the study of cognitive impairment in MS by rs-fMRI, both in study methods and findings. We argue that standardisation of study methods and more model- 
driven research would lay a clearer path towards clinical utility and the potential use as a biomarker of disease state. Despite inconsistent findings in the direction of FC abnormalities associated with worse cognitive function, most studies do show that FC alterations are a key pathological feature. A consensus on a suitable measure of cognitive dysfunction and the definition of impairment, consideration of differences between MS phenotypes and the role of aging processes, and a focus on the relationship between structural and functional connectivity changes would all be required to contribute to a better understanding of the pathology of cognitive impairment in MS.

This review is the first to systematically summarise the rs-fMRI functional connectivity literature on cognitive impairment in MS. However, there are some limitations to consider. First, rs-fMRI is not the only imaging modality for studying functional connectivity. While they were outside the scope of this review, electroencephalography and magnetoencephalography studies may offer additional insights into FC changes associated with cognitive impairment in MS. Similarly, there are other network measures that can be derived from rs-fMRI in addition to FC, such as dynamic FC and graph theory measures. At present the number of studies reporting these measures is small and so we did not consider them separately, but rather grouped them with the FC measure for the purposes of the review. Nevertheless, these metrics provide somewhat different information to the FC metric, which has not been captured in detail in this review. Finally, we did not carry out a formal statistical meta-analysis of the studies in this review. Instead, due to low numbers of homogeneous studies we were limited to tallying the number of studies with a specific feature. As studies start to become more consistent in their use of methods it will become easier to determine across the field whether the hypotheses including disease-specific effects, such as the 'network collapse' model, can suitably explain the patterns of associations that are observed.

In conclusion, this systematic review shows that cognitive impairment in MS is associated with both high and low FC, indicating that any network change seems related to poorer functioning. To better understand the relationship between worsened cognitive function and FC abnormalities, including directional FC changes, there must be standardisation in the field of the 
medRxiv preprint doi: https://doi.org/10.1101/2021.03.18.21253878; this version posted March 20, 2021. The copyright holder for this preprint (which was not certified by peer review) is the author/funder, who has granted medRxiv a license to display the preprint in perpetuity.

All rights reserved. No reuse allowed without permission.

399 definition and measurement of CI, rs-fMRI methodology, and correction and allowances for MS

400 phenotype, lesional changes, and non-MS related pathology from ageing.

401

402

403

404

405

406

407

408

409

\section{Potential Competing Interests}

411 The authors report no potential competing interests relating to this work.

412 


\section{References}

1. Filippi M, Bar-Or A, Piehl F, Preziosa P, Solari A, Vukusic S, et al. Multiple sclerosis. Nat Rev Dis Prim. 2018;4(1):43.

2. Thompson AJ, Baranzini SE, Geurts J, Hemmer B, Ciccarelli O. Multiple sclerosis. Lancet. 2018;391(10130):1622-36.

3. Dobson R, Giovannoni G. Multiple sclerosis - a review. Eur J Neurol. 2019;26(1):27-40.

4. Lassmann H. Multiple sclerosis pathology. Cold Spring Harb Perspect Med. 2018;8(3):116.

5. Charcot JM. Lectures on the disease of the nervous system. Second. J E Adlard; 1888.

6. Benedict RHB. Cognition in multiple sclerosis: Charcot was right. Lancet Neurol. 2020;19(10):810.

7. Benedict RHB, Amato MP, DeLuca J, Geurts JJG. Cognitive impairment in multiple sclerosis: clinical management, MRI, and therapeutic avenues. Lancet Neurol. 2020;19(10):860-71.

8. Fischer M, Kunkel A, Bublak P, Faiss JH, Hoffmann F, Sailer M, et al. How reliable is the classification of cognitive impairment across different criteria in early and late stages of multiple sclerosis? J Neurol Sci. 2014; 343: 91-99.

9. Sumowski JF, Benedict R, Enzinger C, Filippi M, Geurts JJ, Hamalainen P, et al. Cognition in multiple sclerosis: State of the field and priorities for the future. Neurology. 2018;90(6):278-88.

10. Ruet A, Deloire M, Hamel D, Ouallet JC, Petry K, Brochet B. Cognitive impairment, health-related quality of life and vocational status at early stages of multiple sclerosis: A 7-year longitudinal study. J Neurol. 2013;260(3):776-84.

11. Strober LB, Rao SM, Lee J-CC, Fischer E, Rudick R. Cognitive impairment in multiple sclerosis: An 18 year follow-up study. Mult Scler Relat Disord. 2014 Jul;3(4):473-81. 
12. Patti F, Amato MP, Bastianello S, Caniatti L, Di Monte E, Ferrazza P, et al. Effects of immunomodulatory treatment with subcutaneous interferon beta-1a on cognitive decline in mildly disabled patients with relapsing-remitting multiple sclerosis. Mult Scler. 2010 Jan;16(1):68-77.

13. Connick P, Chandran S, Bak TH. Patterns of cognitive dysfunction in progressive MS. Behav Neurol. 2013;27(3):259-65.

14. Johnen A, Landmeyer NC, Bürkner PC, Wiendl H, Meuth SG, Holling H. Distinct cognitive impairments in different disease courses of multiple sclerosis-A systematic review and meta-analysis. Vol. 83, Neuroscience and Biobehavioral Reviews. 2017. p. $568-78$.

15. Johnen A, Burkner P-C, Landmeyer NC, Ambrosius B, Calabrese P, Motte J, et al. Can we predict cognitive decline after initial diagnosis of multiple sclerosis? Results from the German National early MS cohort (KKNMS). J Neurol. 2019 Feb;266(2):386-97.

16. Baird JF, Cederberg KLJ, Sikes EM, Jeng B, Sasaki JE, Sandroff BM, et al. Changes in Cognitive Performance With Age in Adults With Multiple Sclerosis. Cogn Behav Neurol. 2019 Sep;32(3):201-7.

17. Motl RW, Sandroff BM. Current Perspectives on Exercise Training in the Management of Multiple Sclerosis. Expert Rev Neurother. 2020;20(8):855-66.

18. Sandroff BM, DeLuca J. Will behavioral treatments for cognitive impairment in multiple sclerosis become standards-of-care? Int J Psychophysiol. 2020;154(October 2018):67-79.

19. Landmeyer NC, Bürkner P-C, Wiendl H, Ruck T, Hartung H-P, Holling H, et al. Diseasemodifying treatments and cognition in relapsing-remitting multiple sclerosis: A metaanalysis. Neurology. 2020 Jun;94(22):e2373-83.

20. Rocca MA, Amato MP, De Stefano N, Enzinger C, Geurts JJ, Penner IK, et al. Clinical and imaging assessment of cognitive dysfunction in multiple sclerosis. Lancet Neurol. 2015;14(3):302-417.

21. Mori F, Rossi S, Sancesario G, Codeca C, Mataluni G, Monteleone F, et al. Cognitive and cortical plasticity deficits correlate with altered amyloid-beta CSF levels in multiple 
sclerosis. Neuropsychopharmacology. 2011 Feb;36(3):559-68.

22. Castellazzi G, Palesi F, Casali S, Vitali P, Sinforiani E, Wheeler-Kingshott CAM, et al. A comprehensive assessment of resting state networks: bidirectional modification of functional integrity in cerebro-cerebellar networks in dementia. Front Neurosci. 2014;

23. Schoonheim MM, Hulst HE, Brandt RB, Strik M, Wink AM, Uitdehaag BMJ, et al. Thalamus structure and function determine severity of cognitive impairment in multiple sclerosis. Neurology. 2015 Feb;84(8):776-83.

24. Battle M, Alahmadi A, Collorone S, Prados F, Kanber B, Ourselin S. Resting state functional networks and cognitive performance in clinically isolated syndromes. Mult Scler J. 2017;23(3 Supplement 1):813.

25. Bijsterbosch J, Smith S, Beckmann C. Introduction to Resting State fMRI Functional Connectivity. Oxford: Oxford University Press; 2017.

26. Hohenfeld C, Werner CJ, Reetz K. Resting-state connectivity in neurodegenerative disorders: Is there potential for an imaging biomarker? NeuroImage Clin. 2018;18(February):849-70.

27. Romero K, Shammi P, Feinstein A. Neurologists' accuracy in predicting cognitive impairment in multiple sclerosis. Mult Scler Relat Disord. 2015;4(4):291-5.

28. Badhwar AP, Tam A, Dansereau C, Orban P, Hoffstaedter F, Bellec P. Resting-state network dysfunction in Alzheimer's disease: A systematic review and meta-analysis. Alzheimer's Dement Diagnosis, Assess Dis Monit. 2017;8:73-85.

29. Hawellek DJ, Hipp JF, Lewis CM, Corbetta M, Engel AK. Increased functional connectivity indicates the severity of cognitive impairment in multiple sclerosis. Proc Natl Acad Sci U S A. 2011 Nov;108(47):19066-71.

30. Schoonheim MM, Hulst HE, Landi D, Ciccarelli O, Roosendaal SD, Sanz-Arigita EJ, et al. Gender-related differences in functional connectivity in multiple sclerosis. Mult Scler J. 2012;18(2):164-73.

31. Tona F, Petsas N, Sbardella E, Prosperini L, Carmellini M, Pozzilli C, et al. Multiple 
sclerosis: Altered thalamic resting-state functional connectivity and its effect on cognitive function. Radiology. 2014;271(3):814-21.

32. Lin SJ, Kolind S, Liu A, McMullen K, Vavasour I, Wang ZJ, et al. Both Stationary and Dynamic Functional Interhemispheric Connectivity Are Strongly Associated With Performance on Cognitive Tests in Multiple Sclerosis. Front Neurol. 2020;11(June):407.

33. Bonavita S, Gallo A, Sacco R, Corte M Della, Bisecco A, Docimo R, et al. Distributed changes in default-mode resting-state connectivity in multiple sclerosis. Mult Scler J. 2011 Apr;17(4):411-22.

34. Faivre A, Rico A, Zaaraoui W, Crespy L, Reuter F, Wybrecht D, et al. Assessing brain connectivity at rest is clinically relevant in early multiple sclerosis. Mult Scler J. 2012 Sep;18(9):1251-8.

35. Basile B, Castelli M, Monteleone F, Nocentini U, Caltagirone C, Centonze D, et al. Functional connectivity changes within specific networks parallel the clinical evolution of multiple sclerosis. Mult Scler. 2014 Jul;20(8):1050-7.

36. Rocca MA, Valsasina P, Leavitt VM, Rodegher M, Radaelli M, Riccitelli GC, et al. Functional network connectivity abnormalities in multiple sclerosis: Correlations with disability and cognitive impairment. Mult Scler J. 2018;24(4):459-71.

37. Cruz-Gómez ÁJ, Ventura-Campos N, Belenguer A, Ávila C, Forn C. The link between resting-state functional connectivity and cognition in MS patients. Mult Scler J. 2014;20(3):338-48.

38. Schoonheim MM, Meijer KA, Geurts JJG. Network collapse and cognitive impairment in multiple sclerosis. Front Neurol. 2015;6(MAR):82.

39. Schoonheim MM, Penner IK, Aktas O, Rocca MA, Filippi M, Penner IK, et al. Functional reorganization is a maladaptive response to injury - COMMENTARY. Mult Scler J. 2017;23(2):194-6.

40. Rocca MA, Valsasina P, Absinta M, Riccitelli G, Rodegher ME, Misci P, et al. Defaultmode network dysfunction and cognitive impairment in progressive MS. Neurology. 2010 Apr;74(16):1252-9. 
41. Roosendaal SD, Hulst HE, Vrenken H, Feenstra HEM, Castelijns JA, Pouwels PJW, et al. Structural and functional hippocampal changes in multiple sclerosis patients with intact memory function. Radiology. 2010;255(2):595-604.

42. Roosendaal SD, Schoonheim MM, Hulst HE, Sanz-Arigita EJ, Smith SM, Geurts JJG, et al. Resting state networks change in clinically isolated syndrome. Brain. 2010 Jun;133(6):1612-21.

43. Cocozza S, Pontillo G, Russo C, Russo CV, Costabile T, Pepe A, et al. Cerebellum and cognition in progressive MS patients: functional changes beyond atrophy? J Neurol. 2018;265(10):2260-6.

44. Tewarie P, Steenwijk MD, Brookes MJ, Uitdehaag BMJ, Geurts JJG, Stam CJ, et al. Explaining the heterogeneity of functional connectivity findings in multiple sclerosis: An empirically informed modeling study. Hum Brain Mapp. 2018 Jun;39(6):2541-8.

45. Moher D, Shamseer L, Clarke M, Ghersi D, Liberati A, Petticrew M, et al. Preferred reporting items for systematic review and meta-analysis protocols (PRISMA-P) 2015 statement. Syst Rev. 2015;4(1).

46. Downes MJ, Brennan ML, Williams HC, Dean RS. Development of a critical appraisal tool to assess the quality of cross-sectional studies (AXIS). BMJ Open. 2016;6:e011458.

47. Higgins JPT, Altman DG, Gøtzsche PC, Jüni P, Moher D, Oxman AD, et al. The Cochrane Collaboration's tool for assessing risk of bias in randomised trials. BMJ. 2011;343:d5928.

48. Koubiyr I, Besson P, Deloire M, Charre-Morin J, Saubusse A, Tourdias T, et al. Dynamic modular-level alterations of structural-functional coupling in clinically isolated syndrome. Brain. 2019;142(11):3428-39.

49. Lin F, Zivadinov R, Hagemeier J, Weinstock-Guttman B, Vaughn C, Gandhi S, et al. Altered nuclei-specific thalamic functional connectivity patterns in multiple sclerosis and their associations with fatigue and cognition. Mult Scler J. 2019;25(9):1243-54.

50. Manca R, Mitolo M, Stabile MR, Bevilacqua F, Sharrack B, Venneri A. Multiple brain networks support processing speed abilities of patients with multiple sclerosis. Postgrad 
Med. 2019;131(7):523-32.

51. Leavitt VM, Paxton J, Sumowski JF. Default network connectivity is linked to memory status in multiple sclerosis. J Int Neuropsychol Soc. 2014 Oct;20(9):937-44.

52. Petsas N, De Giglio L, González-Quintanilla V, Giuliani M, De Angelis F, Tona F, et al. Functional Connectivity Changes After Initial Treatment With Fingolimod in Multiple Sclerosis. Front Neurol. 2019;10(March):153.

53. Krysko KM, Graves JS, Dobson R, Altintas A, Amato MP, Bernard J, et al. Sex effects across the lifespan in women with multiple sclerosis. Ther Adv Neurol Disord. 2020;13:130.

54. Romascano D, Meskaldji D-E, Bonnier G, Simioni S, Rotzinger D, Lin Y-C, et al. Multicontrast connectometry: a new tool to assess cerebellum alterations in early relapsing-remitting multiple sclerosis. Hum Brain Mapp. 2015 Apr;36(4):1609-19.

55. van Geest Q, Westerik B, van der Werf YD, Geurts JJG, Hulst HE. The role of sleep on cognition and functional connectivity in patients with multiple sclerosis. J Neurol. 2017;264(1):72-80.

56. van Geest Q, Douw L, van 't Klooster S, Leurs CE, Genova HM, Wylie GR, et al. Information processing speed in multiple sclerosis: Relevance of default mode network dynamics. NeuroImage Clin. 2018;19:507-15.

57. Amato M, Portaccio E, Goretti B, Zipoli V, Ricchiuti L, De Caro M, et al. The Rao's Brief Repeatable Battery version B: Normative values with age, education and gender corrections in an Italian population. Mult Scler. 2006;12:787-93.

58. Langdon D, Amato M, Boringa J, Brochet B, Foley F, Fredrikson S, et al. Recommendations for a Brief International Cognitive Assessment for Multiple Sclerosis (BICAMS). Mult Scler J. 2012;18(6):891-8.

59. Benedict RHB, Fischer JS, Archibald CJ, Arnett PA, Beatty WW, Bobholz J, et al. Minimal neuropsychological assessment of MS patients: A consensus approach. Clin Neuropsychol. 2002;16(3):381-97. 
60. Filippi M, Rocca MA. Present and future of fMRI in multiple sclerosis. Expert Rev Neurother. 2013 Dec;13:27-31.

61. Eshaghi A, Riyahi-Alam S, Saeedi R, Roostaei T, Nazeri A, Aghsaei A, et al. Classification algorithms with multi-modal data fusion could accurately distinguish neuromyelitis optica from multiple sclerosis. NeuroImage Clin. 2015;7:306-14.

62. Loitfelder M, Fazekas F, Petrovic K, Fuchs S, Ropele S, Wallner-Blazek M, et al. Reorganization in cognitive networks with progression of multiple sclerosis: insights from fMRI. Neurology. 2011;76(6):526-33.

63. Chard DT, Alahmadi AAS, Audoin B, Charalambous T, Enzinger C, Hulst HE, et al. Mind the gap: from neurons to networks to outcomes in multiple sclerosis. Nat Rev Neurol. 2021;17:173-184.

64. Meijer KA, van Geest Q, Eijlers AJC, Geurts JJG, Schoonheim MM, Hulst HE. Is impaired information processing speed a matter of structural or functional damage in MS?. NeuroImage Clin. 2018;20:844-50.

65. Castellazzi G, Debernard L, Melzer TR, Dalrymple-Alford JC, D’Angelo E, Miller DH, et al. Functional connectivity alterations reveal complex mechanisms based on clinical and radiological status in mild relapsing remitting multiple sclerosis. Front Neurol. 2018;9(AUG):1-15.

66. Azevedo CJ, Cen SY, Jaberzadeh A, Zheng L, Hauser SL, Pelletier D. Contribution of normal aging to brain atrophy in MS. Neurol Neuroimmunol neuroinflammation. 2019;6(6).

67. Bonavita S, Gallo A, Sacco R, Corte M Della, Bisecco A, Docimo R, et al. Distributed changes in default-mode resting-state connectivity in multiple sclerosis. Mult Scler J. 2011;17(4):411-22.

68. d'Ambrosio A, Hidalgo de la Cruz M, Valsasina P, Pagani E, Colombo B, Rodegher M, et al. Structural connectivity-defined thalamic subregions have different functional connectivity abnormalities in multiple sclerosis patients: Implications for clinical correlations. Hum Brain Mapp. 2017;38(12):6005-18. 
69. Eijlers AJC, Meijer KA, Wassenaar TM, Steenwijk MD, Uitdehaag BMJ, Barkhof F, et al. Increased default-mode network centrality in cognitively impaired multiple sclerosis patients. Neurology. 2017 Mar 7;88(10):952-60.

70. Meijer KA, Eijlers AJCC, Douw L, Uitdehaag BMJJ, Barkhof F, Geurts JJGG, et al. Increased connectivity of hub networks and cognitive impairment in multiple sclerosis. Neurology. 2017 May 30;88(22):2107-14.

71. Meijer KA, Eijlers AJC, Geurts JJG, Schoonheim MM. Staging of cortical and deep grey matter functional connectivity changes in multiple sclerosis. J Neurol Neurosurg Psychiatry. 2018 Feb;89(2):205-10.

72. D'Ambrosio A, Valsasina P, Gallo A, De Stefano N, Pareto D, Barkhof F, et al. Reduced dynamics of functional connectivity and cognitive impairment in multiple sclerosis. Mult Scler J. 2020;26(4):476-88.

73. Eijlers AJC, Wink AM, Meijer KA, Douw L, Geurts JJG, Schoonheim MM. Reduced Network Dynamics on Functional MRI Signals Cognitive Impairment in Multiple Sclerosis. Radiology. 2019;292(2):449-57.

74. Cruz-Gómez ÁJ, Aguirre N, Sanchis-Segura C, Ávila C, Forn C. Subcortical grey matter structures in multiple sclerosis: What is their role in cognition? Neuroreport. 2018;29(7):547-52.

75. Eijlers AJC, Meijer KA, van Geest Q, Geurts JJG, Schoonheim MM. Determinants of Cognitive Impairment in Patients with Multiple Sclerosis with and without Atrophy. Radiology. 2018;288(2):544-51.

76. Doshi A, Castellazzi G, Muhlert N, Alahmadi A, Prados F, Wheeler-Kingshott CAM, et al. COGNITIVE DIAGNOSTIC CRITERIA LEAD TO DISTINCT PATTERNS OF FUNCTIONAL CONNECTIVITY IN SECONDARY PROGRESSIVE MS. J Neurol Neurosurg Psychiatry. 2019;90(12):2019.

77. Eijlers AJC, Meijer KA, Wassenaar TM, Steenwijk MD, Uitdehaag BMJ, Barkhof F, et al. Increased default-mode network centrality in cognitively impaired multiple sclerosis patients. Neurology. 2017;88(10):952-60. 
medRxiv preprint doi: https://doi.org/10.1101/2021.03.18.21253878; this version posted March 20, 2021. The copyright holder for this preprint

(which was not certified by peer review) is the author/funder, who has granted medRxiv a license to display the preprint in perpetuity.

All rights reserved. No reuse allowed without permission.

78. Ruet A, Deloire M, Charré-Morin J, Hamel D, Brochet B. Cognitive impairment differs between primary progressive and relapsing-remitting MS. Neurology. 2013;80(16):15018 .

79. Chan D, Binks S, Nicholas JM, Frost C, Cardoso MJ, Ourselin S, et al. Effect of high-dose simvastatin on cognitive, neuropsychiatric, and health-related quality-of-life measures in secondary progressive multiple sclerosis: secondary analyses from the MS-STAT randomised, placebo-controlled trial. Lancet Neurol. 2017 Aug;16(8):591-600.

80. Llufriu S, Martinez-Heras E, Solana E, Sola-Valls N, Sepulveda M, Blanco Y, et al. Structural networks involved in attention and executive functions in multiple sclerosis. NeuroImage Clin. 2017;13:288-96.

81. Solana E, Martinez-Heras E, Martinez-Lapiscina EH, Sepulveda M, Sola-Valls N, Bargallo N, et al. Magnetic resonance markers of tissue damage related to connectivity disruption in multiple sclerosis. NeuroImage Clin. 2018;20:161-8.

82. Llufriu S, Rocca MA, Pagani E, Riccitelli GC, Solana E, Colombo B, et al. Hippocampalrelated memory network in multiple sclerosis: A structural connectivity analysis. Mult Scler J. 2019;25(6):801-10.

83. Tewarie P, Steenwijk MD, Tijms BM, Daams M, Balk LJ, Stam CJ, et al. Disruption of structural and functional networks in long-standing multiple sclerosis. Hum Brain Mapp. 2014 Dec;35(12):5946-61.

84. Enzinger C, Pinter D, Rocca MA, De Luca J, Sastre-Garriga J, Audoin B, et al. Longitudinal fMRI studies: Exploring brain plasticity and repair in MS. Mult Scler. 2016;22(3):269-78.

85. Patel KR, Tobyne S, Porter D, Bireley JD, Smith V, Klawiter E. Structural disconnection is responsible for increased functional connectivity in multiple sclerosis. Brain Struct Funct. 2018 Jun 16;223(5):2519-26.

86. Lapointe E, Li DKB, Traboulsee AL, Rauscher A. What Have We Learned from Perfusion MRI in Multiple Sclerosis?. AJNR Am J Neuroradiol. 2018;39(6):994-1000.

87. Maarouf A, Audoin B, Pariollaud F, Gherib S, Rico A, Soulier E, et al. Increased total 
sodium concentration in gray matter better explains cognition than atrophy in MS.

Neurology. 2017;88(3):289-95.

88. Paling D, Solanky BS, Riemer F, Tozer DJ, Wheeler-Kingshott CAM, Kapoor R, et al. Sodium accumulation is associated with disability and a progressive course in multiple sclerosis. Brain. 2013;136(7):2305-17.

89. Solanky BS, John NA, DeAngelis F, Stutters J, Prados F, Schneider T, et al. NAA is a marker of disability in secondary-progressive MS: A proton MR spectroscopic imaging study. Am J Neuroradiol. 2020;41(12):2209-18.

90. Fox MD, Greicius M. Clinical applications of resting state functional connectivity. Front Syst Neurosci. 2010;4:1-13.

91. Jones DT, Mateen FJ, Lucchinetti CF, Jack CRJ, Welker KM. Default mode network disruption secondary to a lesion in the anterior thalamus. Arch Neurol. 2011 Feb;68(2):242-7.

92. Loitfelder M, Filippi M, Rocca M, Valsasina P, Ropele S, Jehna M, et al. Abnormalities of resting state functional connectivity are related to sustained attention deficits in MS. PLoS One. 2012;7(8):e42862.

93. Janssen AL, Boster A, Patterson BA, Abduljalil A, Prakash RS. Resting-state functional connectivity in multiple sclerosis: An examination of group differences and individual differences. Neuropsychologia. 2013 Nov;51(13):2918-29.

94. Koenig KA, Lowe MJ, Lin J, Sakaie KE, Stone L, Bermel RA, et al. Sex differences in resting-state functional connectivity in multiple sclerosis. Am J Neuroradiol. 2013 Dec;34(12):2304-11.

95. Louapre C, Perlbarg V, García-Lorenzo D, Urbanski M, Benali H, Assouad R, et al. Brain networks disconnection in early multiple sclerosis cognitive deficits: An anatomofunctional study. Hum Brain Mapp. 2014;35(9):4706-17.

96. Schoonheim MM, Geurts J, Wiebenga OT, De Munck JC, Polman CH, Stam CJ, et al. Changes in functional network centrality underlie cognitive dysfunction and physical disability in multiple sclerosis. Mult Scler. 2014 Jul;20(8):1058-65. 
97. Tona F, Petsas N, Sbardella E, Prosperini L, Carmellini M, Pozzilli C, et al. .Multiple sclerosis: altered thalamic resting-state functional connectivity and its effect on cognitive function. Radiology. 2014 Jun;271(3):814-21.

98. Tona F, Petsas N, Sbardella E, Prosperini L, Carmellini M, Pozzilli C, et al. Multiple sclerosis: altered thalamic resting-state functional connectivity and its effect on cognitive function. Radiology. 2014 Jun;271(3):814-21.

99. Wojtowicz M, Mazerolle EL, Bhan V, Fisk JD. Altered functional connectivity and performance variability in relapsing-remitting multiple sclerosis. Mult Scler. 2014 Oct;20(11):1453-63.

100. Hulst HE, Schoonheim MM, Van Geest Q, Uitdehaag BMJ, Barkhof F, Geurts JJG. Memory impairment in multiple sclerosis: Relevance of hippocampal activation and hippocampal connectivity. Mult Scler. 2015 Nov;21(13):1705-12.

101. Sbardella E, Tona F, Petsas N, Upadhyay N, Piattella MC, Filippini N, et al. Functional connectivity changes and their relationship with clinical disability and white matter integrity in patients with relapsing-remitting multiple sclerosis. Mult Scler. 2015;21(13):1681-92.

102. Rocca MA, Valsasina P, Meani A, Falini A, Comi G, Filippi M. Impaired functional integration in multiple sclerosis: a graph theory study. Brain Struct Funct. 2016;221(1):115-31.

103. Sanchis-Segura C, Cruz-Gomez AJ, Belenguer A, Fittipaldi Marquez MS, Avila C, Forn C. Increased regional gray matter atrophy and enhanced functional connectivity in male multiple sclerosis patients. Neurosci Lett. 2016 Sep;630:154-7.

104. Zhou F, Gong H, Chen Q, Wang B, Peng Y, Zhuang Y, et al. Intrinsic functional plasticity of the thalamocortical system in minimally disabled patients with relapsing-remitting multiple sclerosis. Front Hum Neurosci . 2016;10(JAN2016):2.

105. d'Ambrosio A, Hidalgo de la Cruz M, Valsasina P, Pagani E, Colombo B, Rodegher M, et al. Structural connectivity-defined thalamic subregions have different functional connectivity abnormalities in multiple sclerosis patients: Implications for clinical 
correlations. Hum Brain Mapp. 2017;38(12):6005-18.

106. Gabilondo I, Rilo O, Ojeda N, Pena J, Gomez-Gastiasoro A, Mendibe Bilbao M, et al. The influence of posterior visual pathway damage on visual information processing speed in multiple sclerosis. Mult Scler. 2017 Aug;23(9):1276-88.

107. Petracca M, Saiote C, Bender HA, Arias F, Farrell C, Magioncalda P, et al. Synchronization and variability imbalance underlie cognitive impairment in primaryprogressive multiple sclerosis. Sci Rep. 2017 Apr;7:46411.

108. Sbardella E, Upadhyay N, Tona F, Prosperini L, De Giglio L, Petsas N, et al. Dentate nucleus connectivity in adult patients with multiple sclerosis: Functional changes at rest and correlation with clinical features. Mult Scler J. 2017 Apr;23(4):546-55.

109. Gao F, Yin X, Edden RAE, Evans AC, Xu J, Cao G, et al. Altered Hippocampal GABA and Glutamate Levels and Uncoupling from Functional Connectivity in Multiple Sclerosis. Hippocampus. 2018;28(11):813-23.

110. Lin S-J, Vavasour I, Kosaka B, Li DKB, Traboulsee A, MacKay A, et al. Education, and the balance between dynamic and stationary functional connectivity jointly support executive functions in relapsing-remitting multiple sclerosis. Hum Brain Mapp . 2018;39(12):5039-49.

111. D'Ambrosio A, Valsasina P, Gallo A, De Stefano N, Pareto D, Barkhof F, et al. Reduced dynamics of functional connectivity and cognitive impairment in multiple sclerosis. Mult Scler J. 2019;00(0):1-13.

112. Fuchs TA, Benedict RHB, Bartnik A, Choudhery S, Li X, Mallory M, et al. Preserved network functional connectivity underlies cognitive reserve in multiple sclerosis. Hum Brain Mapp. 2019;40(18):5231-41.

113. Karavasilis E, Christidi F, Velonakis G, Tzanetakos D, Zalonis I, Potagas C, et al. Hippocampal structural and functional integrity in multiple sclerosis patients with or without memory impairment: a multimodal neuroimaging study. Brain Imaging Behav . 2019;13(4):1049-59.

114. Bizzo BC, Arruda-Sanchez T, Tobyne SM, Bireley JD, Lev MH, Gasparetto EL, et al. 
Anterior Insular Resting-State Functional Connectivity is Related to Cognitive Reserve in Multiple Sclerosis. J Neuroimaging. 2020;1-5.

115. Carotenuto A, Wilson H, Giordano B, Caminiti SP, Chappell Z, Williams SCR, et al. Impaired connectivity within neuromodulatory networks in multiple sclerosis and clinical implications. J Neurol. 2020;267(7):2042-53.

116. Pasqua G, Tommasin S, Bharti K, Ruggieri S, Petsas N, Piervincenzi C, et al. Restingstate functional connectivity of anterior and posterior cerebellar lobes is altered in multiple sclerosis. Mult Scler J. 2020;1-10.

117. Riccitelli GC, Pagani E, Meani A, Valsasina P, Preziosa P, Filippi M, et al. Cognitive impairment in benign multiple sclerosis: a multiparametric structural and functional MRI study. J Neurol. 2020;(Cc):8-10.

118. Has Silemek AC, Fischer L, Pöttgen J, Penner IK, Engel AK, Heesen C, et al. Functional and structural connectivity substrates of cognitive performance in relapsing remitting multiple sclerosis with mild disability. NeuroImage Clin. 2020;25(January):102177.

119. Soares JM, Conde R, Magalhães RRRR, Marques P, Magalhães RRRR, Gomes L, et al. Alterations in functional connectivity are associated with white matter lesions and information processing efficiency in multiple sclerosis. Brain Imaging Behav. 2020;

120. Welton T, Constantinescu CS, Auer DP, Dineen RA. Graph Theoretic Analysis of Brain Connectomics in Multiple Sclerosis: Reliability and Relationship with Cognition. Brain Connect. 2020;10(2):95-104.

121. Fan J, McCandliss BD, Sommer T, Raz A, Posner MI. Testing the efficiency and independence of attentional networks. J Cogn Neurosci. 2002 Apr;14(3):340-7.

122. Zhao Q, Lv Y, Zhou Y, Hong Z, Guo Q. Short-Term Delayed Recall of Auditory Verbal Learning Test Is Equivalent to Long-Term Delayed Recall for Identifying Amnestic Mild Cognitive Impairment. PLoS One. 2012 Dec 7;7(12):e51157.

123. Rao S. A manual for the Brief Repeatable Battery of Neuropsychological Tests in Multiple Sclerosis. New York: National Multiple Sclerosis Society; 1990. 
124. Benedict R. Brief Visuospatial Memory Test-Revised Professional Manual. Odessa, Florida: Psychological Assessment Resources; 1997.

125. Ruet A, Deloire MSA, Charré-Morin J, Hamel D, Brochet B. A new computerised cognitive test for the detection of information processing speed impairment in multiple sclerosis. Mult Scler J. 2013 Mar 4;19(12):1665-72.

126. Benton A., Hamsher S., Sivan A. Multilingual aplasia examination. 2nd ed. Iowa City: AJA Associates; 1983.

127. Van der Elst W, Van Boxtel MPJ, Van Breukelen GJP, Jolles J. The Concept Shifting Test: adult normative data. Psychol Assess. 2006 Dec;18(4):424-32.

128. Delis D, Kramer J, Kaplan E. California Verbal Learning Test. 2nd ed. San Antonio, Texas: Psychological Corporation; 2000.

129. Kaufman A., Lichtenberger E. Assessing Adolescent and Adult Intelligence. Ed 3rd, editor. New York: Wiley; 2005.

130. Benedict RHB, Schretlen D, Groninger L, Brandt J. Hopkins Verbal Learning Test Revised: Normative Data and Analysis of Inter-Form and Test-Retest Reliability. Clin Neuropsychol. 1998 Feb 1;12(1):43-55.

131. Benton A, Hamsher K, Varney N, Spreen O. Contributions to Neuropsychological Assessment: A Clinical Manual. New York: Oxford; 1983.

132. Salthouse TA. Selective influences of age and speed on associative memory. Am J Psychol. 1995;108(3):381-96.

133. Bucks RS, Willison JR. Development and validation of the Location Learning Test (LLT): A test of visuo-spatial learning designed for use with older adults and in dementia. Clin Neuropsychol. 1997 Aug 1;11(3):273-86.

134. van der Elst W, van Boxtel MPJ, van Breukelen GJP, Jolles J. The Letter Digit Substitution Test: Normative Data for 1,858 Healthy Participants Aged 24-81 from the Maastricht Aging Study (MAAS): Influence of Age, Education, and Sex. J Clin Exp Neuropsychol. 2006 Sep 1;28(6):998-1009. 
135. Hugonot-Diener L, Barbeau E, Michel B, Thomas-Anterion C, Robert P. GREMOIRE: Tests et echelles de la maladie d'Alzheimer et des syndromes apparentes. Marseille: Solal; 2008.

136. Folstein MF, Folstein SE, McHugh PR. "Mini-mental state": A practical method for grading the cognitive state of patients for the clinician. J Psychiatr Res. 1975;12(3):18998.

137. Blair J, Spreen O. Predicting premorbid IQ: A revision of the National Adult Reading Test. Clin Neuropsychol. 1989;3(2):129-36.

138. Fischer JS, Rudick RA, Cutter GR, Reingold SC. The Multiple Sclerosis Functional Composite measure (MSFC): an integrated approach to MS clinical outcome assessment. Mult Scler J. 1999 Aug 1;5(4):244-50.

139. Basso A, Capitani E, Laiacona M. Raven's coloured progressive matrices: normative values on 305 adult normal controls. Funct Neurol. 1987;2(2):189-94.

140. Caffarra P, Vezzadini G, Dieci F, Zonato F, Venneri A. Rey-Osterrieth complex figure: normative values in an Italian population sample. Neurol Sci. 2002;22(6):443-7.

141. Aschenbrenner S, Tucha O, Lange K. Regensburger Wortflüssigkeits-Test $\square$ : RWT $\square$; Handanweisung. Göttingen: Hogrefe, Verl. für Psychologie; 2000.

142. Salthouse TA, Babcock RL, Shaw RJ. Effects of adult age on structural and operational capacities in working memory. Vol. 6, Psychology and Aging. US: American Psychological Association; 1991. p. 118-27.

143. Benedict RHB, DeLuca J, Phillips G, LaRocca N, Hudson LD, Rudick R. Validity of the Symbol Digit Modalities Test as a cognition performance outcome measure for multiple sclerosis. Mult Scler J. 2017 Feb 16;23(5):721-33.

144. Lezak M. Neuropsychological assessment. 3rd ed. New York: Oxford University Press; 2004.

145. Stroop R. Studies of interference in serial verbal reactions. J Exp Psychol. 1935;18(64362). 
146. Zimmermann P, Fimm B. A test battery for attentional performance. In: Applied Neuropsychology of Attention Theory, Diagnosis and Rehabilitation. 2002. p. 110-51.

147. Wechsler D. Test of Premorbid Functioning. San Antonio, Texas: The Psychological Corporation; 2011.

148. Tombaugh T, Rees L. Computerized Test of Information Processing. Toronto: MultiHealth System Inc; 2008.

149. Kokmen E, Smith GE, Petersen RC, Tangalos E, Ivnik RC. The Short Test of Mental Status: Correlations With Standardized Psychometric Testing. Arch Neurol. 1991 Jul $1 ; 48(7): 725-8$.

150. Tombaugh TN. Trail Making Test A and B: Normative data stratified by age and education. Arch Clin Neuropsychol. 2004 Mar 1;19(2):203-14.

151. Lehrl S. Mehrfachwahl-Wortschatz-Intelligenztest (MWT-B). 2nd ed. Erlangen, Germany: Straube; 1991.

152. Patterson J. F-A-S Test BT - Encyclopedia of Clinical Neuropsychology. In: Kreutzer JS, DeLuca J, Caplan B, editors. New York, NY: Springer New York; 2011. p. 1024-6.

153. Helmstaedter C, Durwen HF. [The Verbal Learning and Retention Test. A useful and differentiated tool in evaluating verbal memory performance]. Schweiz Arch Neurol Psychiatr. 1990;141(1):21-30.

154. Robinson A, Heaton R, Lehman R, Stilson D. The utility of the Wisconsin Card Sorting Test in detecting and localizing frontal lobe lesions. J Consult Clin Psychol. 1980;48(5):605-14.

155. Wechsler D. Wechsler memory scale administration and scoring manual. Psychological Corporation; 1997.

156. Holdnack H. Wechsler Test of Adult Reading. San Antonio, Texas: The Psychological Corporation; 2001. 


\section{Figures}

A Voxels in raw data

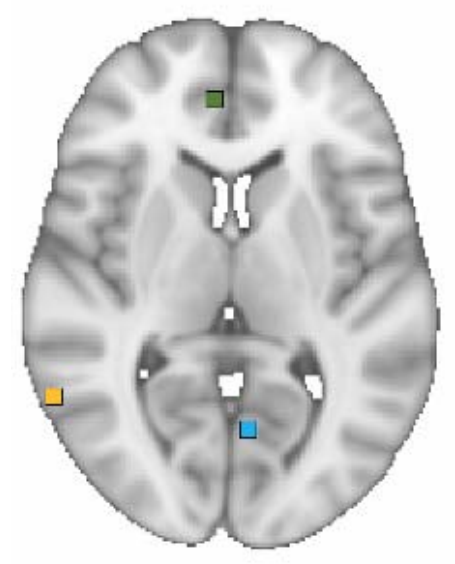

B Correlations between timecourses of voxels

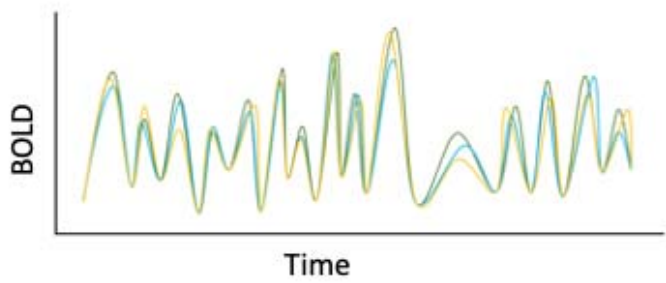

C Functional network

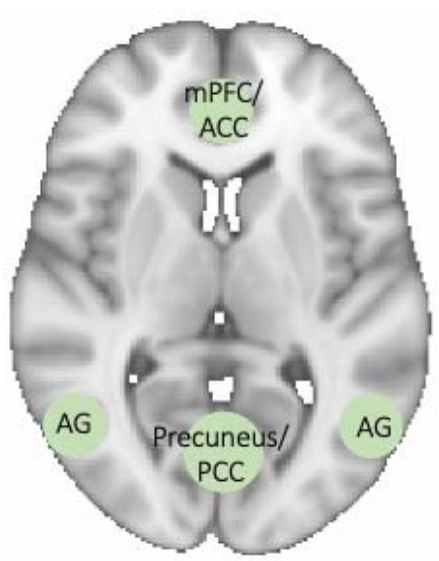

Figure 1. Schematic of functional connectivity and a functional network

Functional connectivity is a measure of the statistical correlation of blood-oxygenation-leveldependent signal timecourses (part B) between any selection of voxels (part A). Voxels or voxel clusters showing high correlations are considered functionally connected, and can be used to identify functional networks such as the default mode network (part $\mathbf{C}$ ).

Abbreviations: $\mathrm{ACC}=$ anterior cingulate cortex $; \mathrm{AG}=$ angular gyrus; $\mathrm{BOLD}=\mathrm{Blood}-$ oxygenation-level-dependent signal; $\mathrm{mPFC}=$ medial prefrontal cortex; $\mathrm{PCC}=$ posterior cingulate cortex 


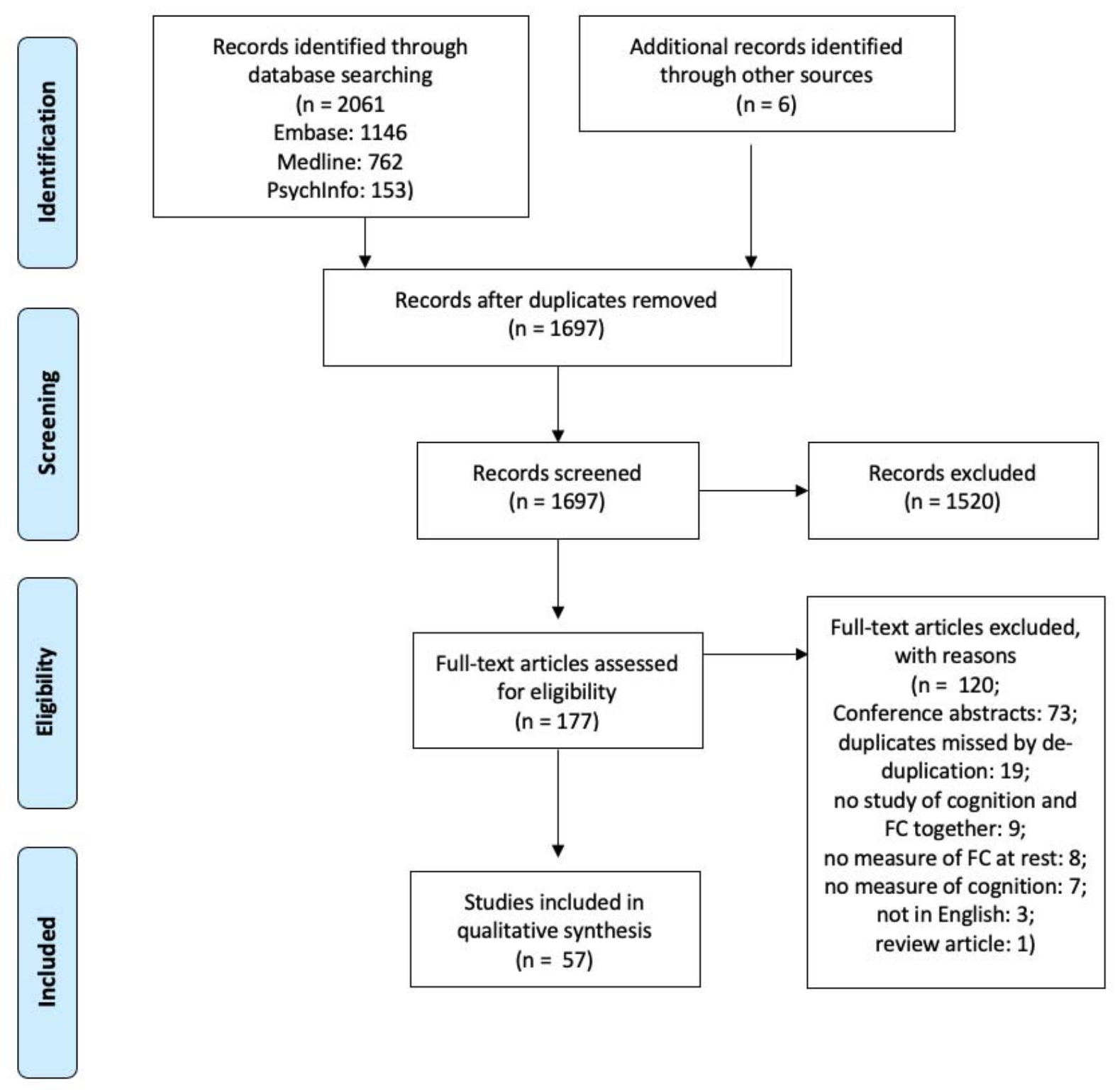

Figure 2. Flow diagram showing identification, screening and selection of records

Figure 1 outlines combined database searches conducted on the $31^{\text {st }}$ October 2019 and on the $22^{\text {nd }}$ October 2020 using the PRISMA protocol for studies of rs-fMRI and cognitive function in MS.

Template from Moher et al. (2015) 
medRxiv preprint doi: https://doi.org/10.1101/2021.03.18.21253878; this version posted March 20, 2021. The copyright holder for this preprint (which was not certified by peer review) is the author/funder, who has granted medRxiv a license to display the preprint in perpetuity.

All rights reserved. No reuse allowed without permission.

20

18

16

14

12

10

8

6

4

2

0

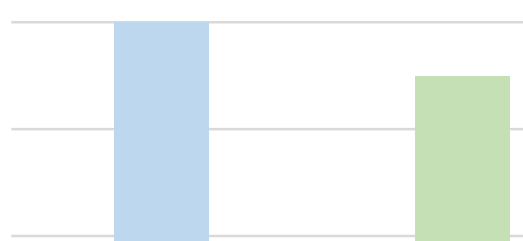

Figure 3. Number of studies reporting an association between poor cognitive test performance and high or low functional connectivity

Eighteen studies reported worse cognition to be associated with high functional connectivity (FC), seventeen with low FC and nine studies with both high and low FC. Seven studies did not find a link between FC abnormalities and cognitive function. Six studies used a method that does not provide information about directional changes in FC in relation to cognitive test performance.

Abbreviations: $\mathrm{FC}=$ functional connectivity. 


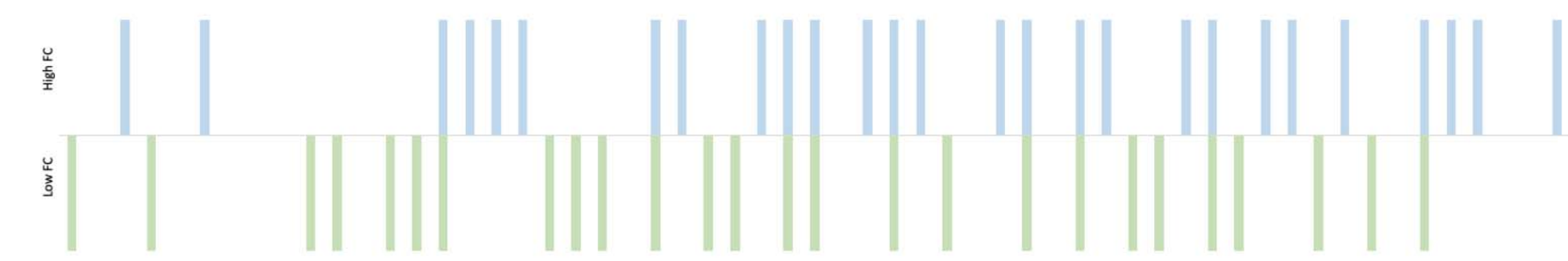

Long disease duration

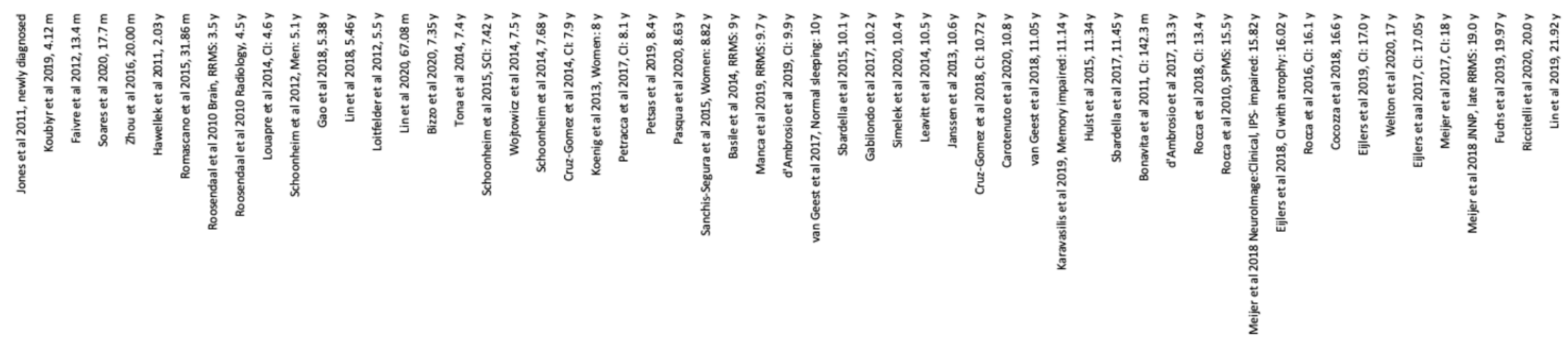

\section{Figure 4. Direction of functional connectivity abnormalities sorted by average disease duration}

Direction of functional connectivity abnormalities associated with worse cognition, sorted by average disease duration of the sample in each study. Because several studies used samples of mixed phenotypes and different disease durations, the following decisions were taken when ordering studies by the disease duration: 1) studies were ordered by the overall disease duration of the sample, when given; 2) studies were ordered by the disease duration of the cognitively impaired group; 3) if there were two cognitively impaired groups, studies were ordered by the disease duration of the more impaired group, or the cognitively impaired group with atrophy, in one case; 4) when the disease duration was only reported for each MS phenotype, or sex, studies were ordered by the disease duration of the larger sample; 5) for a study which had equal numbers of males and females, the study was ordered by the sex with the longer 
disease duration; 6) for one study that used a subset of MS patients that were matched to HC, the study was ordered by the disease duration of the matched subset. Full references are provided in Table 1. 
Table 1. Study characteristics, cognitive assessment and relationship between cognition and functional connectivity

\begin{tabular}{|c|c|c|c|c|c|}
\hline Study & Cohort (n) & Design & Cognitive measures & FC-cognition analysis outcome & $\begin{array}{l}\text { Direction of } \\
\text { FC result }\end{array}$ \\
\hline $\begin{array}{l}\text { Rocca et al. } 2010 \\
(40)\end{array}$ & $\begin{array}{l}\text { SPMS (33) } \\
\text { PPMS (24) } \\
\text { HC (24) }\end{array}$ & $\begin{array}{l}\text { Cross-sectional } \\
\text { ICA }\end{array}$ & $\begin{array}{l}\text { PASAT3, TMT, SST, } \\
\text { WLT, RCFT, VFT }\end{array}$ & $\begin{array}{l}\text { Lower ACC FC within the DMN in MS patients compared } \\
\text { to HC, but more pronounced reductions in cognitively } \\
\text { impaired MS patients. }\end{array}$ & $\downarrow$ \\
\hline $\begin{array}{l}\text { Roosendaal et al. } 2010 \\
\text { (42) }\end{array}$ & $\begin{array}{l}\text { CIS (14) } \\
\text { RRMS (31) } \\
\text { HC (41) }\end{array}$ & $\begin{array}{l}\text { Cross-sectional } \\
\text { ICA }\end{array}$ & Stroop, LLT, LDST & No correlations between FC metrics and cognitive measures. & - \\
\hline $\begin{array}{l}\text { Roosendaal et al. } 2010 \\
\text { (41) }\end{array}$ & $\begin{array}{l}\text { CIS (5) } \\
\text { RRMS (18) } \\
\text { SPMS (2) } \\
\text { HC (30) }\end{array}$ & $\begin{array}{l}\text { Cross-sectional } \\
\text { Seed }\end{array}$ & LLT & $\begin{array}{l}\text { Lower FC in hippocampus bilaterally in MS patients with } \\
\text { intact spatial memory compared to HC. }\end{array}$ & - \\
\hline $\begin{array}{l}\text { Bonavita et al. } 2011 \\
\text { (33) }\end{array}$ & $\begin{array}{l}\text { RRMS (36) } \\
\text { HC (18) }\end{array}$ & $\begin{array}{l}\text { Cross-sectional } \\
\text { ICA }\end{array}$ & BRB-N, Stroop & $\begin{array}{l}\text { Lower ACC and PCC FC in cognitively impaired and } \\
\text { cognitively preserved RRMS compared to HC. Lower PCC } \\
\text { FC in cognitively impaired patients compared to cognitively } \\
\text { preserved. }\end{array}$ & $\downarrow$ \\
\hline $\begin{array}{l}\text { Hawellak et al } 2011 \\
\text { (29) }\end{array}$ & 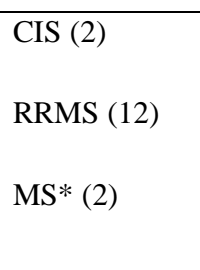 & $\begin{array}{l}\text { Cross-sectional } \\
\text { PCA }\end{array}$ & $\begin{array}{l}\text { PASAT, SDMT, TMT, } \\
\text { Digitspan, Verbal } \\
\text { Intelligence Test } \\
\text { 'Mehrfachwortschatztest- } \\
\text { B," COWAT, subtests of }\end{array}$ & High FC in DMN correlated with low cognitive efficiency. & $\uparrow$ \\
\hline
\end{tabular}




\begin{tabular}{|c|c|c|c|c|c|}
\hline & $\begin{array}{l}\mathrm{HC}(16) \\
\\
\text { *Subtypes not } \\
\text { specified. }\end{array}$ & & TAP & & \\
\hline $\begin{array}{l}\text { Jones et al } 2011 \\
\text { (91) }\end{array}$ & $\begin{array}{l}\text { MS NOS (1) } \\
\text { HC (10) }\end{array}$ & $\begin{array}{l}\text { Case study } \\
\text { ICA }\end{array}$ & $\begin{array}{l}\text { The short test of mental } \\
\text { status }\end{array}$ & $\begin{array}{l}\text { Single patient with cognitive symptoms showed lower FC in } \\
\text { PCC, precuneus and left inferior parietal lobe of DMN } \\
\text { compared to HC. }\end{array}$ & $\downarrow$ \\
\hline $\begin{array}{l}\text { Faivre et al. } 2012 \\
\text { (34) }\end{array}$ & $\begin{array}{l}\text { RRMS (13) } \\
\text { HC (14) }\end{array}$ & $\begin{array}{l}\text { Cross-sectional } \\
\text { ICA }\end{array}$ & BRB-N & $\begin{array}{l}\text { High FC in DMN correlated with decreased performance in } \\
\text { semantic fluency task. High FC in dorsal FPN and right } \\
\text { ventral FPN correlated with worse PASAT scores. }\end{array}$ & $\uparrow$ \\
\hline $\begin{array}{l}\text { Schoonheim et al. } 2012 \\
\text { (30) }\end{array}$ & $\begin{array}{l}\text { RRMS (26) } \\
\text { SPMS (4) } \\
\text { HC (30) }\end{array}$ & $\begin{array}{l}\text { Cross-sectional } \\
\text { SCA } \\
\text { GT }\end{array}$ & LLT, LDST & $\begin{array}{l}\text { Low FC and network efficiency in male MS correlated with } \\
\text { visuospatial memory. }\end{array}$ & $\downarrow$ \\
\hline $\begin{array}{l}\text { Janssen et al. } 2013 \\
\text { (93) }\end{array}$ & $\begin{array}{l}\text { RRMS (28) } \\
\text { HC (28) }\end{array}$ & $\begin{array}{l}\text { Cross-sectional } \\
\text { ICA }\end{array}$ & $\begin{array}{l}\text { PASAT3, letter comparison } \\
\text { and pattern comparison } \\
\text { tasks }\end{array}$ & $\begin{array}{l}\text { No correlations between FC in any network and processing } \\
\text { speed measure. }\end{array}$ & - \\
\hline
\end{tabular}




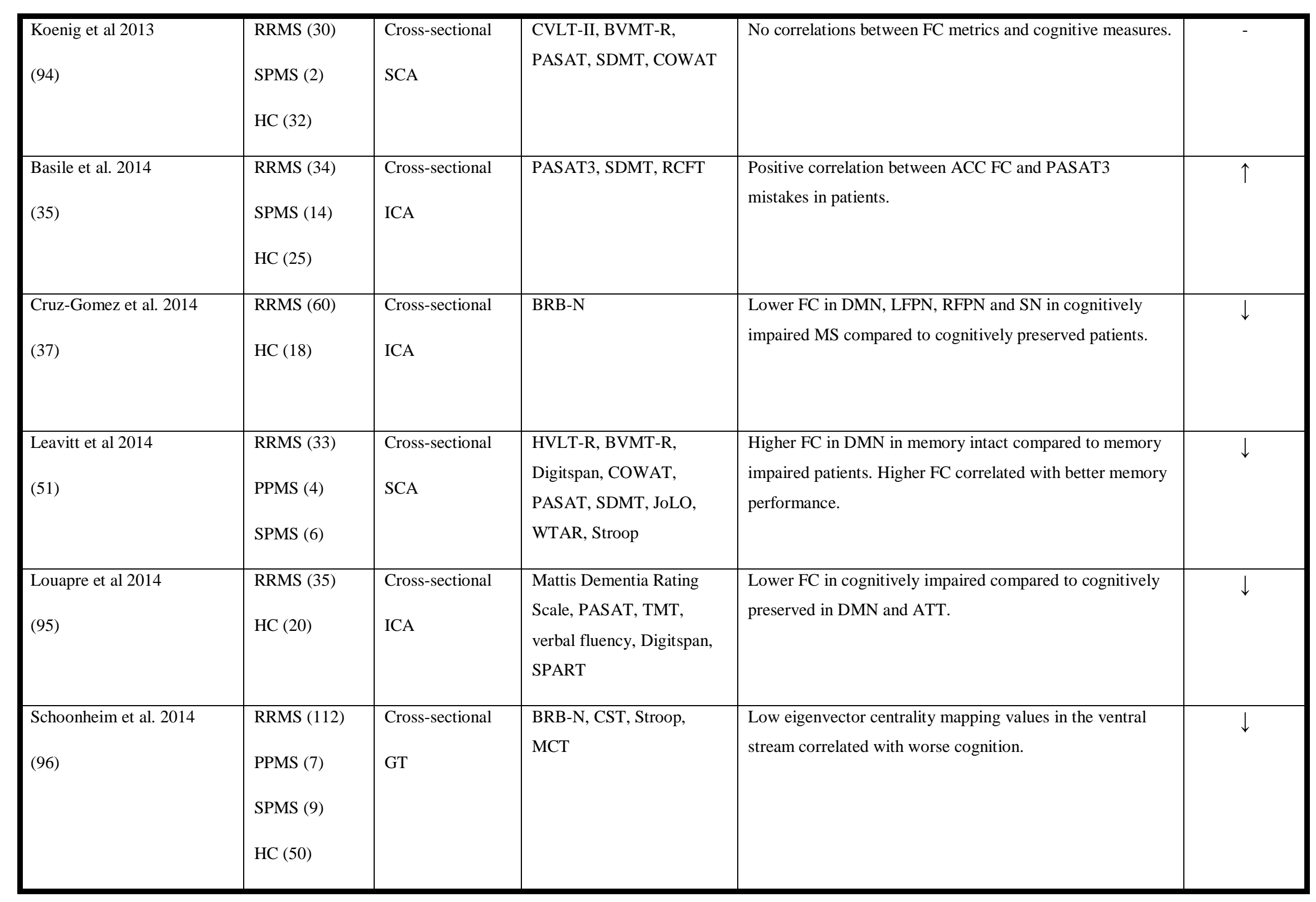




\begin{tabular}{|c|c|c|c|c|c|}
\hline $\begin{array}{l}\text { Tona et al. } 2014 \\
\text { (97)(98) }\end{array}$ & $\begin{array}{l}\text { RRMS (48) } \\
\text { HC (24) }\end{array}$ & $\begin{array}{l}\text { Cross-sectional } \\
\text { SCA }\end{array}$ & PASAT3 & $\begin{array}{l}\text { Inverse correlation of thalamo-cortical resting state } \\
\text { functional connections with PASAT3 score. }\end{array}$ & $\uparrow$ \\
\hline $\begin{array}{l}\text { Wojtowicz et al } 2014 \\
\text { (99) }\end{array}$ & $\begin{array}{l}\text { RRMS (18) } \\
\text { HC (16) }\end{array}$ & $\begin{array}{l}\text { Cross-sectional } \\
\text { SCA }\end{array}$ & $\begin{array}{l}\text { The computerised test of } \\
\text { information processing }\end{array}$ & $\begin{array}{l}\text { Better cognitive task performance associated with high FC } \\
\text { in DMN regions. }\end{array}$ & $\downarrow$ \\
\hline $\begin{array}{l}\text { Hulst et al } 2015 \\
\text { (100) }\end{array}$ & $\begin{array}{l}\text { RRMS (40) } \\
\text { SPMS (17) } \\
\text { HC (28) }\end{array}$ & $\begin{array}{l}\text { Cross-sectional } \\
\text { SCA }\end{array}$ & $\begin{array}{l}\text { Dutch equivalent of CVLT, } \\
\text { LLT, Digit Span, WLG, } \\
\text { LDST }\end{array}$ & $\begin{array}{l}\text { Memory impairment was predicted by (among other } \\
\text { variables) high hippocampal FC. }\end{array}$ & $\uparrow$ \\
\hline $\begin{array}{l}\text { Romascano et al } 2015 \\
\text { (54) }\end{array}$ & $\begin{array}{l}\text { RRMS (28) } \\
\text { HC (16) }\end{array}$ & $\begin{array}{l}\text { Cross-sectional } \\
\text { GT }\end{array}$ & BRB-N & Relationship between FC and cognition not assessed. & - \\
\hline $\begin{array}{l}\text { Sbardella et al } 2015 \\
\text { (101) }\end{array}$ & $\begin{array}{l}\text { RRMS (30) } \\
\text { HC (24) }\end{array}$ & $\begin{array}{l}\text { Cross-sectional } \\
\text { ICA }\end{array}$ & $\begin{array}{l}\text { Mini Mental State } \\
\text { Examination, PASAT }\end{array}$ & $\begin{array}{l}\text { FC of executive control and medial visual networks } \\
\text { correlated inversely with PASAT scores. }\end{array}$ & $\uparrow$ \\
\hline $\begin{array}{l}\text { Schoonheim et al. } 2015 \\
\text { (23) }\end{array}$ & $\begin{array}{l}\text { RRMS (133) } \\
\text { PPMS (15) } \\
\text { SPMS (9) } \\
\text { HC (47) }\end{array}$ & $\begin{array}{l}\text { Cross-sectional } \\
\text { SCA }\end{array}$ & $\begin{array}{l}\text { BRB-N, Stroop, CST, } \\
\text { MCT }\end{array}$ & $\begin{array}{l}\text { Higher thalamic FC in severely cognitively impaired } \\
\text { patients compared to cognitively preserved patients. }\end{array}$ & $\uparrow$ \\
\hline $\begin{array}{l}\text { Rocca et al. } 2016 \\
\text { (102) }\end{array}$ & $\begin{array}{l}\text { RRMS (121) } \\
\text { BMS (45) } \\
\text { SPMS (80) } \\
\text { HC (55) }\end{array}$ & $\begin{array}{l}\text { Cross-sectional } \\
\text { GT }\end{array}$ & PASAT3 & $\begin{array}{l}\text { Abnormal network properties in cognitively impaired } \\
\text { compared to cognitively preserved patients: lower mean } \\
\text { network degree, global efficiency and hierarchy, higher path } \\
\text { length, fewer hubs in left frontal cortex and thalamus. }\end{array}$ & $\downarrow$ \\
\hline
\end{tabular}




\begin{tabular}{|c|c|c|c|c|c|}
\hline $\begin{array}{l}\text { Sanchis-Segura et al } 2016 \\
\text { (103) }\end{array}$ & $\begin{array}{l}\text { RRMS (56) } \\
\text { HC (63) }\end{array}$ & $\begin{array}{l}\text { Cross-sectional } \\
\text { SCA }\end{array}$ & BRB-N & Positive correlation between FC and cognitive performance. & $\downarrow$ \\
\hline $\begin{array}{l}\text { Zhou et al } 2016 \\
\text { (104) }\end{array}$ & $\begin{array}{l}\text { RRMS (20) } \\
\text { HC (20) }\end{array}$ & $\begin{array}{l}\text { Cross-sectional } \\
\text { SCA }\end{array}$ & PASAT & No correlations between FC metrics and cognitive measures. & - \\
\hline $\begin{array}{l}\text { D'Ambrosio et al } 2017 \\
\text { (105) }\end{array}$ & $\begin{array}{l}\text { RRMS (136) } \\
\text { PPMS (9) } \\
\text { SPMS (42) } \\
\text { HC (94) }\end{array}$ & $\begin{array}{l}\text { Cross-sectional } \\
\text { SCA }\end{array}$ & BRB-N & $\begin{array}{l}\text { Higher thalamic FC in cognitively impaired compared to } \\
\text { cognitively preserved patients. }\end{array}$ & $\uparrow$ \\
\hline $\begin{array}{l}\text { Eijlers et al. } 2017 \\
(77)\end{array}$ & $\begin{array}{l}\text { RRMS (243) } \\
\text { SPMS (53) } \\
\text { PPMS 36) } \\
\text { HC (96) }\end{array}$ & $\begin{array}{l}\text { Cross-sectional } \\
\text { GT }\end{array}$ & $\begin{array}{l}\text { BRNB, SRT, WLG, } \\
\text { SDMT, Stroop, MCT }\end{array}$ & $\begin{array}{l}\text { Widespread high DMN network centrality in cognitively } \\
\text { impaired compared to cognitively preserved patients. Some } \\
\text { low centrality in CI, in occipital and sensorimotor areas. }\end{array}$ & $\downarrow \uparrow$ \\
\hline $\begin{array}{l}\text { Gabilondo et al } 2017 \\
\text { (106) }\end{array}$ & $\begin{array}{l}\text { RRMS (22) } \\
\text { PPMS (1) } \\
\text { SPMS (7) } \\
\text { HC (28) }\end{array}$ & Cross-sectional & $\begin{array}{l}\text { TMT, Salthouse Perceptual } \\
\text { Comparison Test, SDMT }\end{array}$ & $\begin{array}{l}\text { Low visual processing speed correlated with both low and } \\
\text { high } \mathrm{FC} \text {, in the medial visual component. }\end{array}$ & $\downarrow \uparrow$ \\
\hline $\begin{array}{l}\text { Meijer et al } 2017 \\
\text { (70) }\end{array}$ & $\begin{array}{l}\text { RRMS (243) } \\
\text { PPMS (36) } \\
\text { SPMS (53) } \\
\text { HC (96) }\end{array}$ & $\begin{array}{l}\text { Cross-sectional } \\
\text { ICA }\end{array}$ & BRB-N & $\begin{array}{l}\text { Higher FC in cognitively impaired compared to cognitively } \\
\text { preserved patients in DMN and FPN. }\end{array}$ & $\uparrow$ \\
\hline
\end{tabular}




\begin{tabular}{|c|c|c|c|c|c|}
\hline $\begin{array}{l}\text { Petracca et al } 2017 \\
\text { (107) }\end{array}$ & $\begin{array}{l}\text { PPMS (25) } \\
\text { HC (20) }\end{array}$ & $\begin{array}{l}\text { Cross-sectional } \\
\text { SCA }\end{array}$ & MACFIMS & $\begin{array}{l}\text { Pattern of both lower and higher FC in cognitively impaired } \\
\text { compared to cognitively preserved patients. }\end{array}$ & $\downarrow \uparrow$ \\
\hline $\begin{array}{l}\text { Sbardella et al } 2017 \\
\text { (108) }\end{array}$ & $\begin{array}{l}\text { RRMS (54) } \\
\text { HC (24) }\end{array}$ & $\begin{array}{l}\text { Cross-sectional } \\
\text { SCA }\end{array}$ & PASAT & $\begin{array}{l}\text { Positive correlation between FC of dentate nuclei and } \\
\text { PASAT performance. }\end{array}$ & $\downarrow$ \\
\hline $\begin{array}{l}\text { Van Geest et al } 2017 \\
\text { (55) }\end{array}$ & $\begin{array}{l}\text { RRMS (52) } \\
\text { SPMS (18) } \\
\text { HC (40) }\end{array}$ & $\begin{array}{l}\text { Cross-sectional } \\
\text { SCA }\end{array}$ & $\begin{array}{l}\text { Dutch equivalent of CVLT, } \\
\text { LLT, Digitspan, WLG, } \\
\text { LDST }\end{array}$ & $\begin{array}{l}\text { Lower FC in sleep disturbed patients, but sleep disturbed } \\
\text { patients did not differ from normally sleeping in cognitive } \\
\text { test performance. (No direct analysis of FC at rest and } \\
\text { cognition.) }\end{array}$ & - \\
\hline $\begin{array}{l}\text { Cocozza et al } 2018 \\
\text { (43) }\end{array}$ & $\begin{array}{l}\text { Progressive } \\
\text { MS* (29) } \\
\text { HC (22) } \\
\\
\text { *Number of } \\
\text { PPMS relative } \\
\text { to SPMS not } \\
\text { reported }\end{array}$ & $\begin{array}{l}\text { Cross-sectional } \\
\text { SCA }\end{array}$ & BICAMS & $\begin{array}{l}\text { Inverse relationship between cerebellar FC and BVMT } \\
\text { scores. }\end{array}$ & $\uparrow$ \\
\hline $\begin{array}{l}\text { Cruz-Gomez et al } 2018 \\
\text { (74) }\end{array}$ & $\begin{array}{l}\text { RRMS (36) } \\
\text { HC (18) }\end{array}$ & $\begin{array}{l}\text { Cross-sectional } \\
\text { SCA }\end{array}$ & BRB-N & $\begin{array}{l}\text { Higher FC in cognitively impaired compared to cognitively } \\
\text { preserved patients between right caudate and bilateral } \\
\text { orbitofrontal cortex. }\end{array}$ & $\uparrow$ \\
\hline $\begin{array}{l}\text { Eijlers et al } 2018 \\
(75)\end{array}$ & $\begin{array}{l}\text { RRMS (239) } \\
\text { PPMS (35) } \\
\text { SPMS (53) }\end{array}$ & $\begin{array}{l}\text { Cross-sectional } \\
\text { GT }\end{array}$ & BRB-N & $\begin{array}{l}\text { Higher network centrality in PCC in cognitively impaired } \\
\text { compared to cognitively preserved patients regardless of } \\
\text { presence of GM atrophy. }\end{array}$ & $\uparrow$ \\
\hline
\end{tabular}




\begin{tabular}{|c|c|c|c|c|c|}
\hline & HC (96) & & & & \\
\hline $\begin{array}{l}\text { Lin et al } 2018 \\
\text { (110) }\end{array}$ & $\begin{array}{l}\text { RRMS (27) } \\
\text { HC (15) }\end{array}$ & $\begin{array}{l}\text { Cross-sectional } \\
\text { SCA }\end{array}$ & $\begin{array}{l}\text { Digit span, arithmetic, } \\
\text { letter-numbering } \\
\text { sequencing, symbol search, } \\
\text { coding subtests from the } \\
\text { WAIS IV, VFT, WCST, } \\
\text { TMT. }\end{array}$ & $\begin{array}{l}\text { Better executive functions and processing speed correlated } \\
\text { with higher dynamic and stationary FC. }\end{array}$ & $\downarrow$ \\
\hline $\begin{array}{l}\text { Meijer et al. } 2018 \\
\text { (71) }\end{array}$ & $\begin{array}{l}\text { RRMS (241) } \\
\text { SPMS (53) } \\
\text { HC (96) }\end{array}$ & $\begin{array}{l}\text { Cross-sectional } \\
\text { SCA }\end{array}$ & $\begin{array}{l}\text { BRB-N, CST, MCT, } \\
\text { Stroop }\end{array}$ & $\begin{array}{l}\text { High within-DGM and DGM-cortex FC correlated to worse } \\
\text { cognition. }\end{array}$ & $\uparrow$ \\
\hline $\begin{array}{l}\text { Meijer et al } 2018 \\
(64)\end{array}$ & $\begin{array}{l}\text { RRMS (243) } \\
\text { PPMS (36) } \\
\text { SPMS (51) } \\
\text { HC (96) }\end{array}$ & $\begin{array}{l}\text { Cross-sectional } \\
\text { SCA }\end{array}$ & BRB-N & $\begin{array}{l}\text { Higher FC in patients with impaired information processing } \\
\text { speed compared to those with preserved. }\end{array}$ & $\uparrow$ \\
\hline $\begin{array}{l}\text { Rocca et al. } 2018 \\
\text { (36) }\end{array}$ & $\begin{array}{l}\text { RRMS (119) } \\
\text { PPMS (13) } \\
\text { SPMS (41) } \\
\text { BMS (29) }\end{array}$ & $\begin{array}{l}\text { Cross-sectional } \\
\text { SCA }\end{array}$ & BRB-N & $\begin{array}{l}\text { Lower FC in DMN and DAN in cognitively impaired } \\
\text { compared to cognitively preserved patients. Higher FC in } \\
\text { thalamic network in cognitively impaired compared to } \\
\text { cognitively preserved patients. }\end{array}$ & $\downarrow \uparrow$ \\
\hline
\end{tabular}




\begin{tabular}{|c|c|c|c|c|c|}
\hline & $\begin{array}{l}\text { CIS (13) } \\
\text { HC (98) }\end{array}$ & & & & \\
\hline $\begin{array}{l}\text { Van Geest et al. } 2018 \\
\text { (56) }\end{array}$ & $\begin{array}{l}\text { MS* (29) } \\
\text { HC (19) } \\
\text { *Subtypes not } \\
\text { specified. }\end{array}$ & $\begin{array}{l}\text { Cross-sectional } \\
\text { SCA }\end{array}$ & LDST, SDMT, Stroop & $\begin{array}{l}\text { Information processing task performance predicted by } \\
\text { difference in dynamic FC between task and rest states. (No } \\
\text { direct analysis of FC at rest and cognition.) }\end{array}$ & - \\
\hline $\begin{array}{l}\text { D'Ambrosio et al } 2019 \\
\text { (111) }\end{array}$ & $\begin{array}{l}\text { RRMS (62) } \\
\text { HC (65) }\end{array}$ & $\begin{array}{l}\text { Cross-sectional } \\
\text { ICA }\end{array}$ & BRB-N, WCST & $\begin{array}{l}\text { Lower dynamic FC in the subcortical and default mode } \\
\text { networks in cognitively impaired compared to cognitively } \\
\text { preserved patients. Static FC showed pattern of both lower } \\
\text { and higher FC in cognitively impaired compared to } \\
\text { cognitively preserved patients. }\end{array}$ & $\downarrow \uparrow$ \\
\hline $\begin{array}{l}\text { Eijlers et al } 2019 \\
\text { (73) }\end{array}$ & $\begin{array}{l}\text { RRMS (197) } \\
\text { PPMS (23) } \\
\text { SPMS (47) } \\
\text { HC (96) }\end{array}$ & $\begin{array}{l}\text { Cross-sectional } \\
\text { GT }\end{array}$ & BRB-N & $\begin{array}{l}\text { Lower dynamic FC in cognitively impaired compared to } \\
\text { cognitively preserved patients in DMN regions. }\end{array}$ & $\downarrow$ \\
\hline $\begin{array}{l}\text { Fuchs et al } 2019 \\
\text { (112) }\end{array}$ & $\begin{array}{l}\text { RRMS (48) } \\
\text { PPMS (2) } \\
\text { SPMS (24) } \\
\text { HC (29) }\end{array}$ & $\begin{array}{l}\text { Cross-sectional } \\
\text { ICA }\end{array}$ & $\begin{array}{l}\text { BICAMS, North American } \\
\text { Adult Reading Test }\end{array}$ & $\begin{array}{l}\text { Cognitive reserve predicted preservation of functional } \\
\text { connectivity describe accumulation of GM atrophy and } \\
\text { additionally attenuated structural network disruption. }\end{array}$ & - \\
\hline
\end{tabular}




\begin{tabular}{|c|c|c|c|c|c|}
\hline $\begin{array}{l}\text { Karavasilis et al } 2019 \\
\text { (113) }\end{array}$ & $\begin{array}{l}\text { CIS (16) } \\
\text { RRMS (15) } \\
\text { HC (16) }\end{array}$ & $\begin{array}{l}\text { Cross-sectional } \\
\text { SCA }\end{array}$ & BRB-N & $\begin{array}{l}\text { Compared to memory impaired patients, memory preserved } \\
\text { patients showed higher FC between left hippocampus and } \\
\text { right temporo-occipital fusiform/lingual gyrus, and lower } \\
\text { FC between left hippocampus and right supramarginal } \\
\text { gyrus. }\end{array}$ & $\downarrow \uparrow$ \\
\hline $\begin{array}{l}\text { Koubiyr et al } 2019 \\
(48)\end{array}$ & $\begin{array}{l}\text { CIS (52) } \\
\text { HC (20) }\end{array}$ & $\begin{array}{l}\text { Longitudinal } \\
\text { GT }\end{array}$ & $\begin{array}{l}\text { TAP, PASAT3, SRT, } \\
\text { BVMT-R, Stroop test, } \\
\text { WLG, computerised speed } \\
\text { cognitive test, SDMT } \\
\text { alertness test }\end{array}$ & $\begin{array}{l}\text { No significant correlations between structural-functional } \\
\text { coupling and neuropsychological variables at either baseline } \\
\text { or } 1 \text { year follow up. }\end{array}$ & - \\
\hline $\begin{array}{l}\text { Lin et al } 2019 \\
(49)\end{array}$ & $\begin{array}{l}\text { RRMS (37) } \\
\text { PPMS (3) } \\
\text { SPMS (24) } \\
\text { HC (26) }\end{array}$ & $\begin{array}{l}\text { Cross-sectional } \\
\text { ICA }\end{array}$ & $\begin{array}{l}\text { SDMT, CVLT, BVMT-R, } \\
\text { PASAT }\end{array}$ & $\begin{array}{l}\text { Negative correlation between SDMT scores and FC in MS } \\
\text { group. No other cognitive measures correlated with FC. }\end{array}$ & $\uparrow$ \\
\hline $\begin{array}{l}\text { Manca et al } 2019 \\
(50)\end{array}$ & $\begin{array}{l}\text { RRMS (40) } \\
\text { SPMS (25) }\end{array}$ & $\begin{array}{l}\text { Cross-sectional } \\
\text { ICA }\end{array}$ & $\begin{array}{l}\text { Mini Mental State } \\
\text { Examination, Raven's } \\
\text { Coloured Progressive } \\
\text { Matrices, TMT, Stroop, } \\
\text { Semantic and Phonemic } \\
\text { Fluency Tests }\end{array}$ & $\begin{array}{l}\text { FC correlated positively with cognitive test performance in } \\
\text { LFPN, and negatively in SN and DMN. No correlations in } \\
\text { RFPN. }\end{array}$ & $\downarrow \uparrow$ \\
\hline $\begin{array}{l}\text { Petsas et al } 2019 \\
\text { (52) }\end{array}$ & RRMS (32) & $\begin{array}{l}\text { Longitudinal } \\
\text { SCA }\end{array}$ & PASAT 2 and $3 \mathrm{sec}$ & $\begin{array}{l}\text { Low resting state FC before a task (baseline FC) over a } 6 \\
\text { month period was inversely related to PASAT } 3 \\
\text { performance, but not PASAT 2. No relationships were found } \\
\text { for the resting state FC metric obtained after a task. }\end{array}$ & $\uparrow$ \\
\hline
\end{tabular}




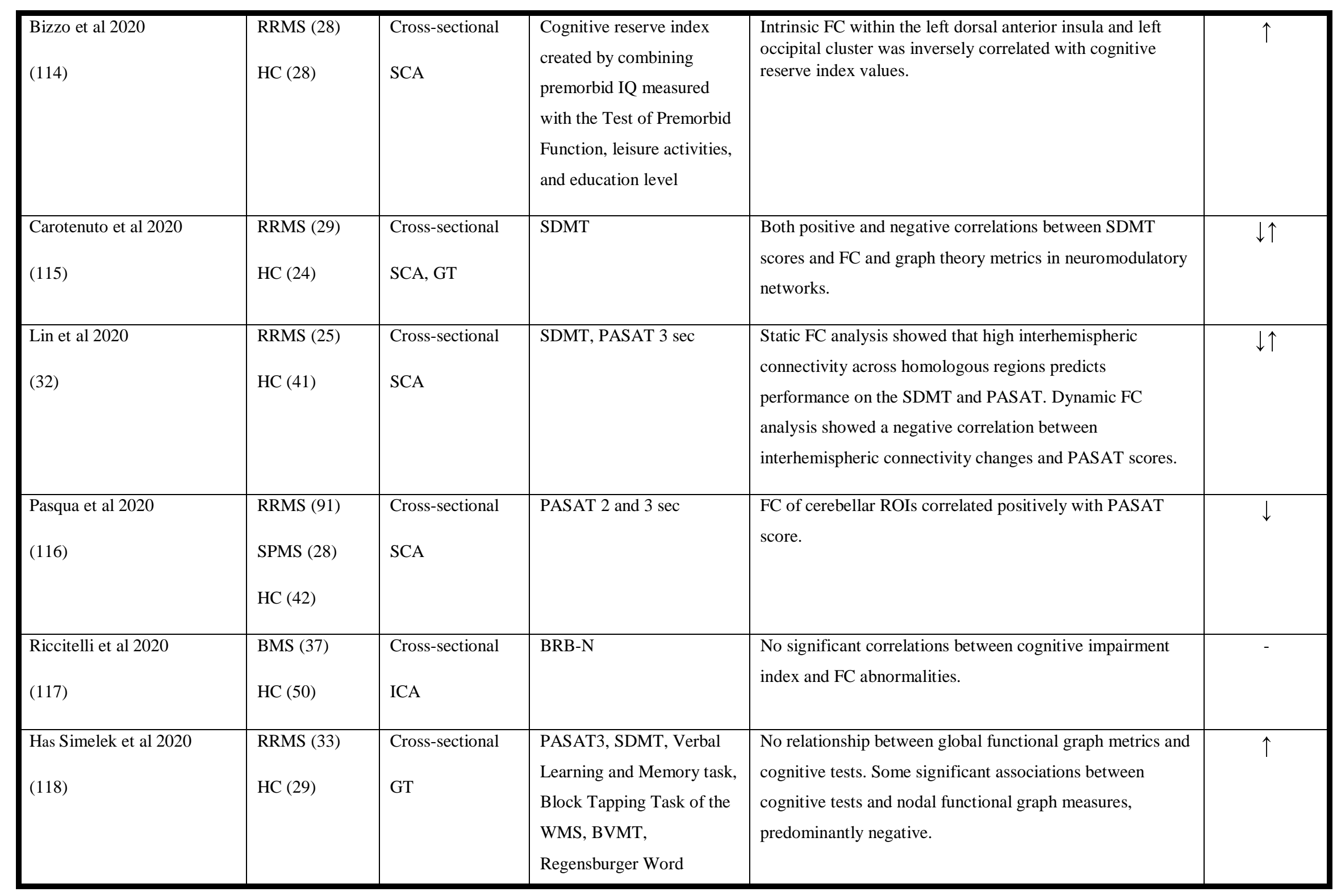




\begin{tabular}{|c|c|c|c|c|c|}
\hline & & & Fluency Task & & \\
\hline $\begin{array}{l}\text { Soares et al } 2020 \\
\text { (119) }\end{array}$ & $\begin{array}{l}\text { RRMS (21) } \\
\text { HC (17) }\end{array}$ & $\begin{array}{l}\text { Cross-sectional } \\
\text { ICA, GT }\end{array}$ & MACFIMS, PASAT & $\begin{array}{l}\text { Whole brain connectome FC correlated positively with } \\
\text { information processing efficiency composite. For specific } \\
\text { RSNs, there were positive correlations between information } \\
\text { processing efficiency and FC of the DMN, precuneus, } \\
\text { sensorimotor and ventral attentional networks. }\end{array}$ & $\downarrow$ \\
\hline $\begin{array}{l}\text { Welton et al } 2020 \\
\text { (120) }\end{array}$ & $\begin{array}{l}\text { RRMS (22) } \\
\text { SPMS (15) } \\
\text { HC (23) }\end{array}$ & Longitudinal, GT & $\begin{array}{l}\text { PASAT } 3 \text { sec, SDMT, } \\
\text { attention network test }\end{array}$ & $\begin{array}{l}\text { FC graph theory network metrics were significantly } \\
\text { predictive for the PASAT3 and SDMT, but not for the } \\
\text { attention network test. Worse performance on the PASAT } \\
\text { was predicted by increased clustering and modulatory, } \\
\text { longer average path lengths and less small worldness. Worse } \\
\text { performance on the SDMT was predicted by less small } \\
\text { worldness, lower global efficiency and longer average path } \\
\text { lengths. }\end{array}$ & - \\
\hline
\end{tabular}

$\uparrow$ arrow up indicates that high FC is associated with worse cognition, $\downarrow$ arrow down indicates that low FC is associated with worse cognition, - dash indicates negative result or that the study did not assess directionality in the relationship between FC and cognition

Abbreviations: $\mathrm{FC}=$ functional connectivity, ICA=independent component analysis, $\mathrm{SCA}=\mathrm{Seed}$ based connectivity analysis, GT=graph theory, MS=multiple sclerosis, RRMS=relapsing-remitting multiple sclerosis, PPMS=primary progressive multiple sclerosis, SPMS=secondary progressive multiple sclerosis, CIS=clinically isolated syndrome, BMS=benign multiple sclerosis, $\mathrm{HC}=$ healthy controls, $\mathrm{ACC}=$ anterior cingulate cortex, $\mathrm{PCC}=$ posterior cingulate cortex, $\mathrm{DGM}=\mathrm{deep}$ grey matter, $\mathrm{DMN}=\mathrm{def} a u l t$ mode network, FPN=frontoparietal network, LFPN=left FPN, RFPN=right FPN, SN=salience network, ATT=attentional network,

$\mathrm{DAN}=$ dorsal attention network 
Abbreviations and references of cognitive measures: Attention network test (121); Auditory verbal learning test (122);

BICAMS=Brief International Cognitive Assessment for MS (58); BRB-N=Brief Repeatable Battery of Neuropsychological tests (123); BVMT-R=Brief Visuospatial Memory Test-Revised (124); Computerised speed cognitive test (125); COWAT=Controlled Oral Words Association Test (126); CST=Concept Shifting Test (127); CVLT=California Verbal Learning Test (128); Digitspan (129); HVLT-R=Hopkins Verbal Learning Test-revised (130); JoLO=Judgement of Line Orientation (131); Letter comparison and pattern comparison tasks (132); LLT=Location Learning Test (133); LDST=letter digit substitution test (134); MACFIMS=Minimal Assessment of Cognitive Function in Multiple Sclerosis (59); Mattis Dementia Rating Scale (135); MCT=Memory Comparison Test; Mini Mental State Examination (136); North American Reading Test (137); PASAT=Paced Auditory Serial Additions Test (138); Raven's Coloured Progressive Matrices (139); RCFT=Rey-Osterrieth Complex Figure Test (140); Regensburger Word Fluency Task (141); Salthouse Perceptual Comparison Test (142); SDMT=symbol digit modalities test (143); Semantic and Phonemic Fluency Tests (144); SPART = 10/36 Spatial Recall Test (123); SRT=Selective Reminding Test (123); SST=Short Story Test; Stroop=Stroop Interference Test (145); TAP=Test of Attentional Performance (146); Test of Premorbid Function (147); The computerised test of information processing (148); The short test of mental status (149); TMT-trail making test (150); Verbal Intelligence Test Mehrfachwortschatztest-B (151); VFT=Verbal Fluency Test (152); Verbal Learning and Memory task (153); WCST=Wisconsin card sorting test (154); WAIS=Wechsler Adult Intelligence Scale (129); WMS=Wechsler Memory Scale (155); WLG=word list generation (123); WLT=word learning test; WTAR=Wechsler Test of Adult Reading (156) 


\section{A Voxels in raw data}

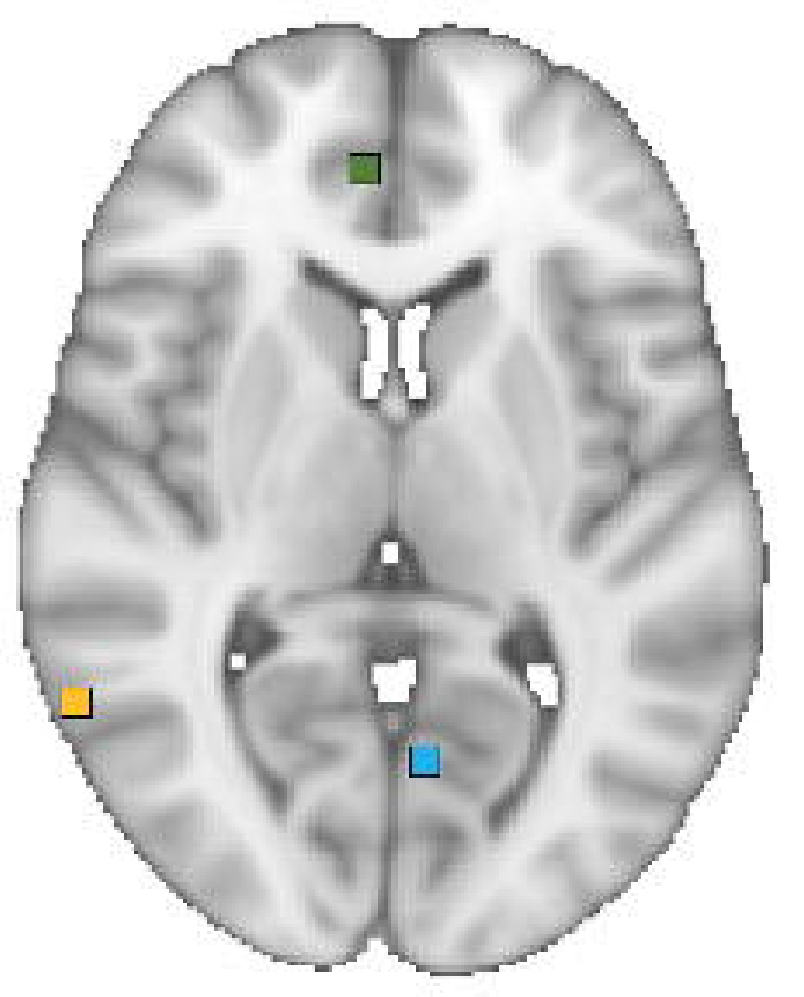

B Correlations between timecourses of voxels

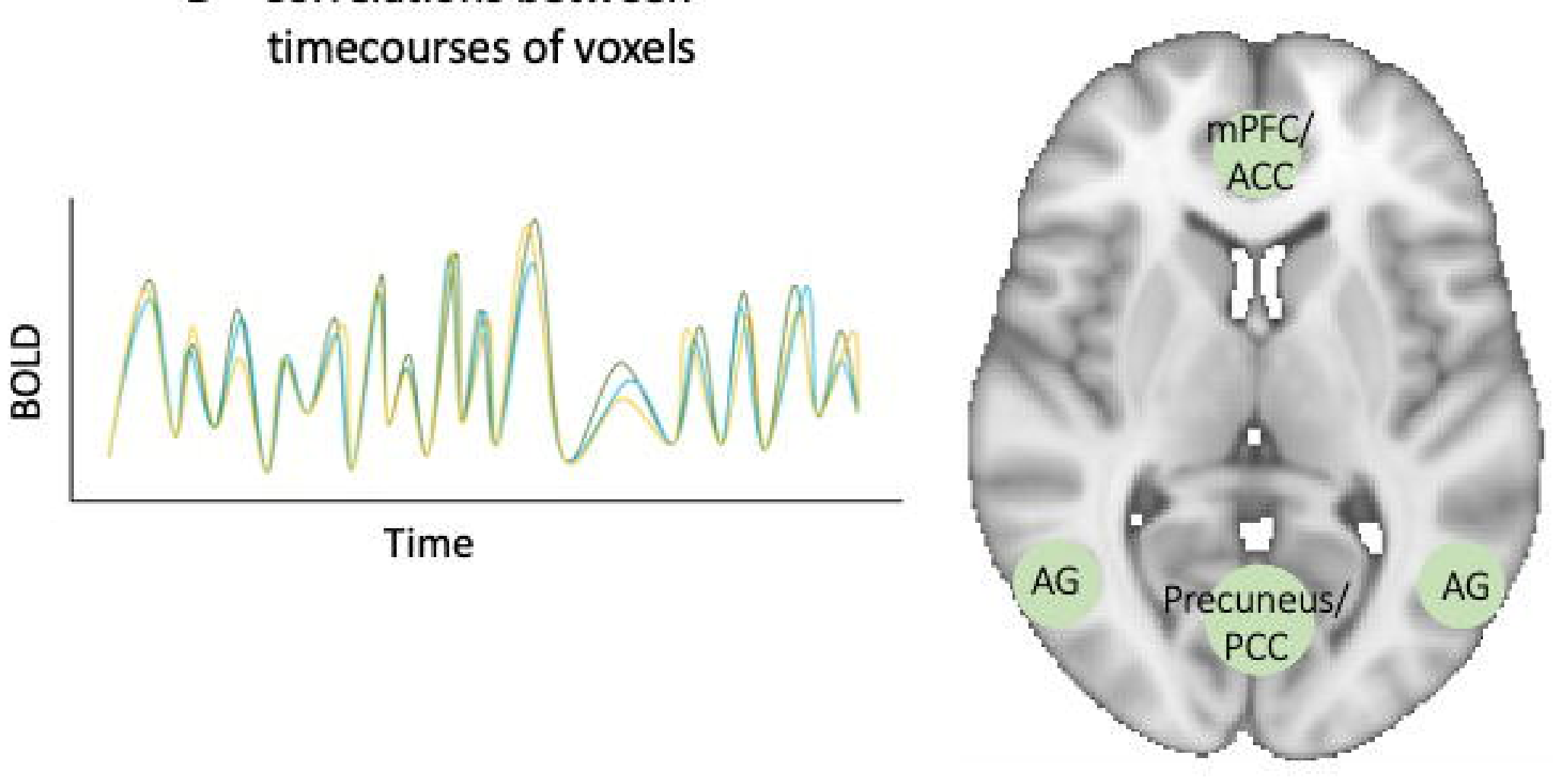

C Functional network 
8

6

4

2

0

High FC

Low FC

Both high and low FC

Negative result

Method does not

inform about direction 


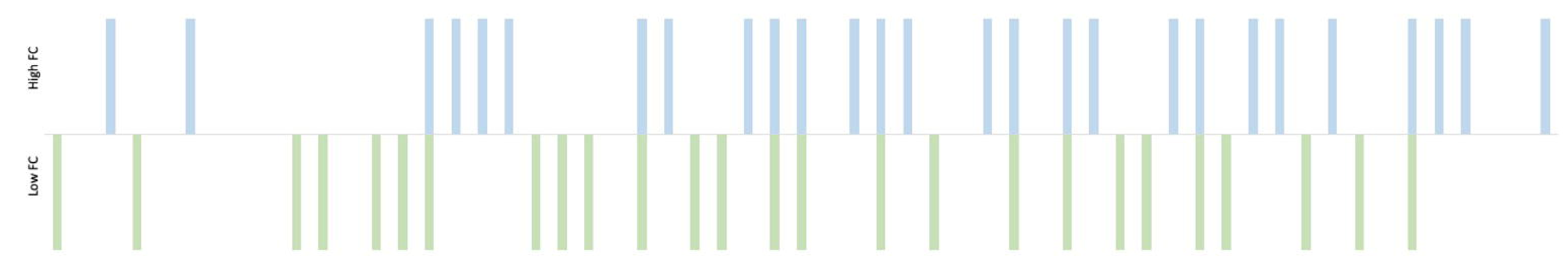

Short disease duration

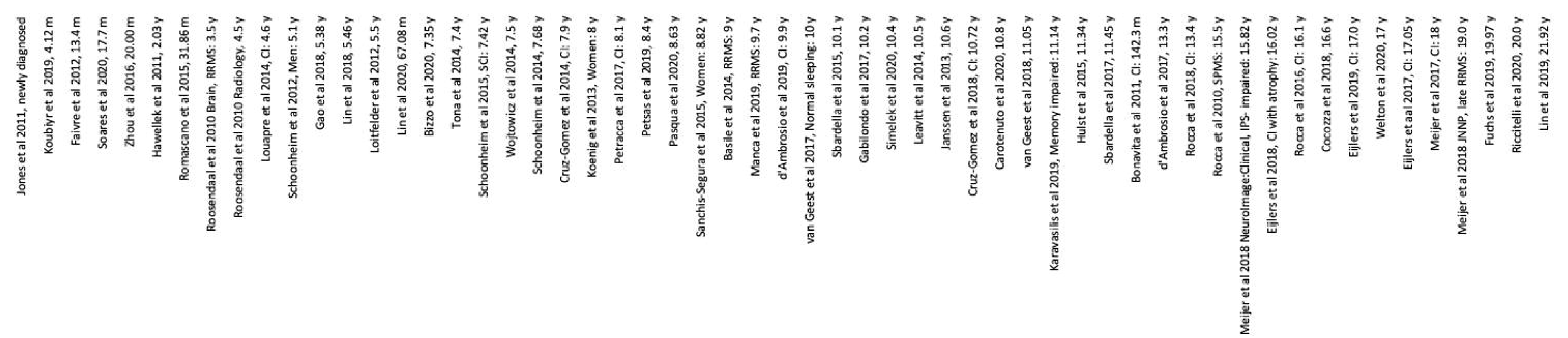

